\title{
The co-existence of two growth hormone receptors in teleost fish and their differential signal transduction, tissue distribution and hormonal regulation of expression in seabream
}

\author{
Baowei Jiao ${ }^{1,2}$, Xigui Huang ${ }^{1,3}$, Chi Bun Chan ${ }^{1}$, Li Zhang ${ }^{3}$, Deshou Wang ${ }^{3}$ and \\ Christopher H K Cheng ${ }^{1}$
}

${ }^{1}$ Department of Biochemistry and 2 the Environmental Science Programme, The Chinese University of Hong Kong, Shatin, New Territories, Hong Kong, China

${ }^{3}$ Key Laboratory of Aquatic Science of Chongqing, Faculty of Life Sciences, Southwest University, Beibei, Chongqing 400715, China

(Requests for offprints should be addressed to C H K Cheng; Email: chkcheng @ cuhk.edu.hk)

(All authors contributed equally to this work.)

\begin{abstract}
Two genomic contigs of putative growth hormone receptors (GHRs) were identified in fugu and zebrafish genomes by in silico analysis, suggesting the presence of two GHR subtypes in a single teleost species. We have tested this hypothesis by cloning the full-length cDNA sequence of a second GHR subtype from the black seabream in which the first GHR subtype had been previously reported by us. In addition, we had also cloned the sequences of both GHR subtypes from two other fish species, namely the Southern catfish and the Nile tilapia. Phylogenetic analysis of known GHR sequences from various vertebrates revealed that fish GHRs cluster into two distinct clades, viz. GHR1 and GHR2. One clade (GHR1), containing 6 to 7 extracellular cysteine residues, is structurally more akin to the non-teleost GHRs. The other clade (GHR2), containing only 4 to 5 extracellular cysteine residues, is unique to teleosts and is structurally more divergent from the non-teleost GHRs. In addition, we had examined the biological activities of both GHR subtypes from seabream using a number of reporter transcription assays in cultured eukaryotic cells and demonstrated that both of them were able to activate the Spi 2.1 and $\beta$-casein promoters upon receptor stimulation in a ligand specific manner. In contrast, only GHR1 but not GHR2 in seabream could trigger the c-fos promoter activity, indicating that the two GHR subtypes possess some differences in their signal transduction mechanisms. Also, the expression of GHR2 is significantly higher than GHR1 in many tissues of the seabream including the gonad, kidney, muscle, pituitary and spleen. In vivo hormone treatment data indicated that cortisol upregulated hepatic GHR1 expression in seabream but not GHR2, whereas testosterone decreased hepatic GHR2 expression but not GHR1. On the other hand, hepatic expression of both GHR1 and GHR2 in seabream was decreased by estradiol treatment.
\end{abstract}

Journal of Molecular Endocrinology (2006) 36, 23-40

\section{Introduction}

Growth hormone $(\mathrm{GH})$ interacts with $\mathrm{GH}$ receptor (GHR) on target tissues to evoke the post-receptor signaling events. Apart from promoting somatic growth (Kopchick \& Andry 2000), GH is also involved in other biological functions such as reproduction (Trudeau 1997), immunity (Yada et al. 1999), and osmoregulation in fish (Sakamoto et al. 1997). GHR belongs to the hematopoietin cytokine receptor superfamily (Moutoussamy et al. 1998) that includes GHR, prolactin receptor (PRLR), and a number of other cytokine receptors. Certain common characteristics are found among members of this superfamily. For example, all members of this superfamily possess an extracellular $\mathrm{N}$-terminal ligand-binding domain and a single transmembrane domain. The extracellular domain of each receptor contains several pairs of conserved cysteine residues and two fibronectin III domains. A WSXWS motif is present in almost all members of this superfamily but in the case of mammalian GHR this is substituted by an YXXFS motif. In addition, there are two conserved regions within the intracellular domain termed Box 1 and Box 2 that are important for signal transduction of the receptor. The proline-rich Box 1 region is the site of Janus kinase 2 (JAK2) binding and is essential for the signaling functions of GHR (VanderKuur et al. 1995). Box 2 contains about 15 amino acid (aa) residues and is believed to be involved in the internalization of the receptor (Govers et al. 1999).

The GHR cDNA sequences of more than 10 fish species have been reported. In general, fish GHRs share some common features as their mammalian orthologs including the conserved positions of several pairs of 
extracellular cysteine residues as well as the presence of the Box 1 and Box 2 regions. However, when the aa sequences of various fish GHRs were aligned, it was intriguing to note that they were clustered into two clades. One clade, represented by the reported GHRs of most teleosts, contains 6 to 7 extracellular cysteine residues. The other clade, represented by the reported salmonid GHRs, contains 5 extracellular cysteine residues. This initial observation (Tse et al. 2003) has led to the suggestion that these two types of fish GHRs represent two lineages of GHR in teleost evolution with some fish species expressing one type of GHR and the rest expressing the other. This assumption is now challenged by the finding that two genomic contigs of putative GHRs could be identified in both the fugu (Fugu rubripes) and zebrafish (Danio rerio) genomes, suggesting the presence of two subtypes of GHR in a single teleost species. The present study reports the identification and functional expression of a novel GHR subtype (sbGHR2) in black seabream (Acanthopagrus schlegeli) which is distinct from the classical GHR (sbGHR1) previously reported by us (Tse et al. 2003). During the preparation of this manuscript, Saera-Vila et al. (2005) have reported the sequences of two GHRs in gilthead seabream (Sparus aurata). However, no functional study on this additional fish GHR subtype has been performed and it is not known whether this second GHR subtype in fish bears any biological significance. In the present study we have expressed this newly identified sbGHR2 in cultured eukaryotic cells and demonstrated that it is functionally active. We have also compared its signal transduction activities viz-à-viz sbGHR1. In addition, the tissue distribution of the two GHR subtypes in seabream and their responsiveness in gene expression to different hormones have also been investigated. Furthermore, we have isolated the full-length sequences of both GHR subtypes from two other fish species, viz. the Southern catfish (Silurus meridionalis) and Nile tilapia (Oreochromis niloticus), providing further evidence for the co-existence of two GHR subtypes in a single fish species.

\section{Materials and methods}

\section{Identification of genomic contigs in fugu and zebrafish genomes corresponding to GHR}

Genomic contigs corresponding to GHR in fugu and zebrafish were identified by comparing the known fish GHR sequences with the fugu and zebrafish genome sequences available on the National Center for Biotechnology Information (NCBI) database (Poulter \& Butler 1998), using the Basic Local Alignment Search Tool (BLAST) program from which the putative fugu and zebrafish GHR1 and GHR2 cDNA sequences could be deduced.

\section{Isolation of full-length sbGHR2 cDNA sequence}

A cDNA fragment of the sbGHR2 was obtained by a nested polymerase chain reaction (PCR) approach as described previously (Tse et al. 2003) using a seabream liver cDNA library as the template. In the first round, the PCR was carried out with an initial denaturation at $94{ }^{\circ} \mathrm{C}$ for $2 \mathrm{~min}$, followed by 36 cycles of $94^{\circ} \mathrm{C}$ for $30 \mathrm{~s}$, $55^{\circ} \mathrm{C}$ for $30 \mathrm{~s}$ and $72^{\circ} \mathrm{C}$ for $1 \mathrm{~min}$. This was followed by a final step at $72{ }^{\circ} \mathrm{C}$ for $10 \mathrm{~min}$. In the nested PCR, the reaction conditions were identical to the first round of PCR except that the annealing temperature was increased to $58{ }^{\circ} \mathrm{C}$. The degenerate primers sbGHR2-F1 and sbGHR2-R3 were used in the first round of PGR whereas sbGHR2-F2 and sbGHR2-R2 were used in the nested reaction. Sequence information of all the primers used in the present study is listed in Table 1. The amplicons were resolved on a $1 \%$ agarose gel and the target DNA fragment was purified by the QIAquick Gel Extraction Kit (Qiagen). The fragment was then cloned into pBlueScript II SK+ vector (Stratagene, La Jolla, CA, USA) and the sequence determined using a BigDye Terminator Cycle Sequencing Kit (Applied Biosystem, Forster City, CA, USA) on an ABI Prism 3100 autosequencer (Applied Biosystem).

Gene specific primers for sbGHR2 were designed from the determined nucleotide sequence of the cDNA fragment obtained. The full-length cDNA sequence of sbGHR2 was then obtained by a semi-nested PCR approach using the seabream liver cDNA library as template. Two rounds of PCR were performed to obtain the $5^{\prime}$ end sequence. In the first round, a 36-cycle PCR $\left(94{ }^{\circ} \mathrm{C} 30 \mathrm{~s}, 58^{\circ} \mathrm{C} 30 \mathrm{~s}, 72^{\circ} \mathrm{C} 45 \mathrm{~s}\right)$ was performed using $\mathrm{T} 7$ and sbGHR2-R5 as primers. In the second round of PCR, T7 and sbGHR2-R4 were used as primers in a 30-cycle reaction of identical conditions as the first round. The $3^{\prime}$ end sequence was similarly obtained. The first round of PCR was a 25 -cycle reaction $\left(94^{\circ} \mathrm{C} 30\right.$ s, $55^{\circ} \mathrm{C}$ $30 \mathrm{~s}, 72{ }^{\circ} \mathrm{C} 2.5 \mathrm{~min}$ ) using sbGHR2-F4 and pSport $1 \cdot 1$ as primers. In the second round PCR, sbGHR2-F5 and pSport $1 \cdot 1$ were used as primers in a 36 -cycle reaction of identical conditions as the first round.

\section{Isolation of full-length GHR1 and GHR2 cDNA sequences from Southern catfish and Nile tilapia}

The full-length GHR1 and GHR2 sequences of two other teleost species, viz. Southern catfish and Nile tilapia, were obtained from the liver of the fish by RT-PCR followed by rapid amplification of cDNA ends (RACE).

Southern catfish GHR1: Southern catfish liver first strand cDNA was synthesized using the SMART RACE First Strand cDNA Synthesis Kit (BD Biosciences, Palo Alto, CA,USA). A semi-nested RT-PCR approach was employed to obtain a cDNA fragment of the Southern 
Table 1 Nucleotide sequences of the primers used

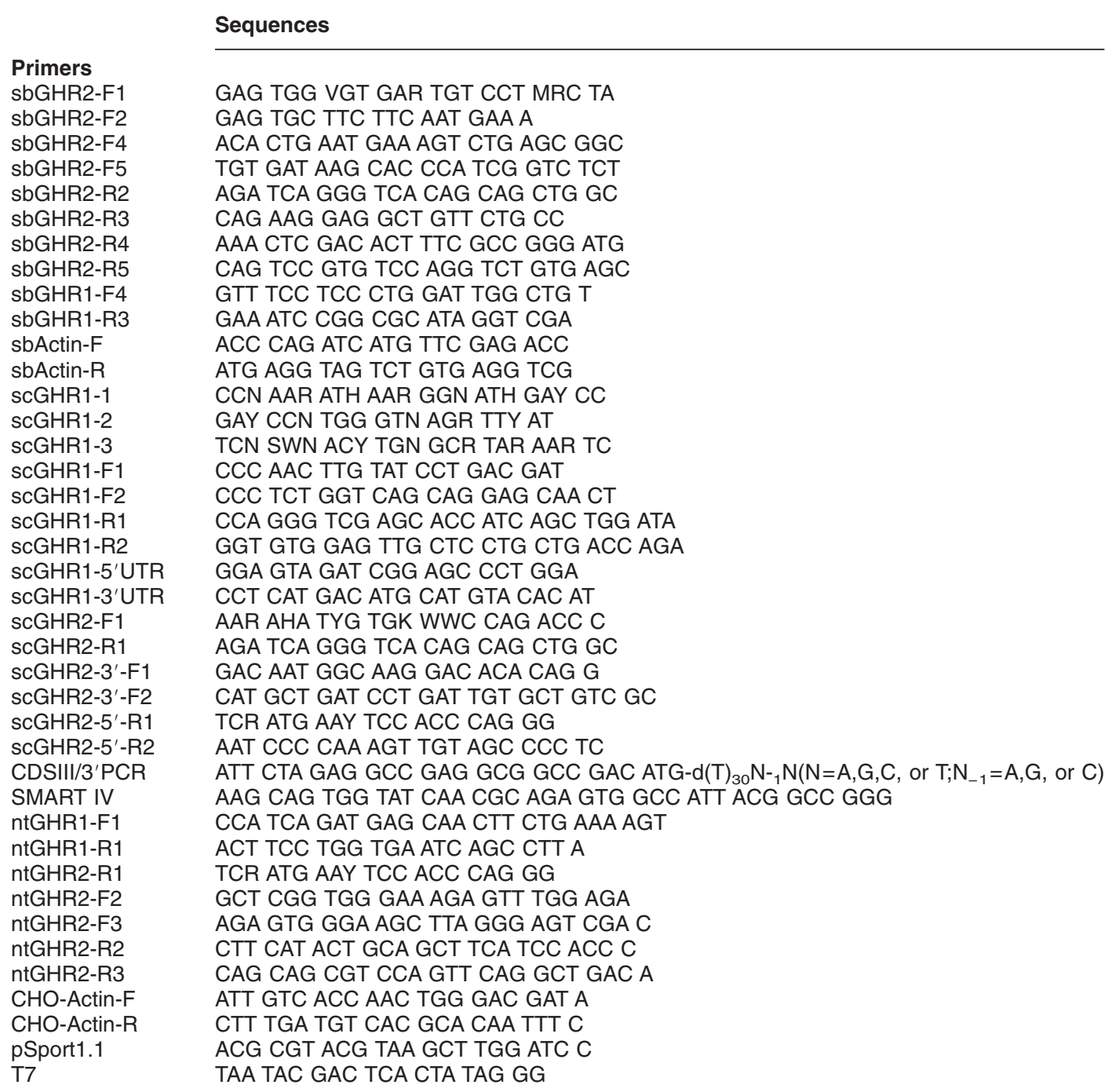

catfish GHR1, using scGHR1-1 and scGHR1-3 as primers in the first round of PCR, and scGHR1-2 and scGHR $1-3$ as primers in the second round of PCR. Then $3^{\prime}$ RACE and 5' RACE were performed to obtain the $3^{\prime}$ and $5^{\prime}$ cDNA ends respectively. Four gene specific primers were used for the RACE reactions: viz. scGHR1-F1, scGHR1-F2, scGHR1-R1, and scGHR1R2. After sequencing the RACE products, two gene specific primers, viz. scGHR $1-5^{\prime} \mathrm{UTR}$ and scGHR 1$3^{\prime} \mathrm{UTR}$, were further designed from the $5^{\prime}$-untranslated region (UTR) and $3^{\prime}$-UTR respectively, and were used to amplify the full-length sequence from first-strand cDNA prepared from liver. The sequence was then determined again to confirm the validity of the entire nucleotide sequence. This final validation step, which has been applied to all the full-length cDNA sequences reported in the present study, is essential to ensure that the composite sequences obtained from the various PCRs and RACE reactions indeed correspond to the real full-length sequences.

Southern catfish GHR2: A cDNA fragment was obtained from the liver first strand cDNA using scGHR2-F1 and scGHR2-R1 as primers. Based on the determined sequence of this cDNA fragment, gene specific primers were designed to obtain the $3^{\prime}$ and $5^{\prime}$ ends by RACE. For 3' RACE, the first round of PCR was performed using scGHR2-3'-F1 and CDSIII/ 3'PCR as primers, followed by a nested PCR using scGHR2-3'-F2 and CDSIII/3'PCR as primers. For 5' RACE, the first round of PCR was performed using 
SMART IV and scGHR2-5'-R1 as primers, followed by a nested PGR using SMART IV and scGHR2$5^{\prime}-\mathrm{R} 2$ as primers.

Nile tilapia GHR1: According to the sequence of Mozambique tilapia GHR and other known GHRs, two primers, viz. ntGHR1-F1 and ntGHR1-R1, located in the $5^{\prime}$-UTR and $3^{\prime}$-UTR respectively, were designed to amplify the entire coding region of the Nile tilapia GHR1 from the liver first strand cDNA.

Nile tilapia GHR2: The primer scGHR1-R1 was used to obtain a fragment of the Nile tilapia GHR2 using a single primer approach (Parks et al. 1991, Hermann et al. 2000). For 3' RACE, the first round of PCR was performed using ntGHR2-F2 and CDSIII/3'PGR as primers, followed by a nested PGR using ntGHR2-F3 and CDSIII/3'PCR as primers. For 5' RACE, the first round of PCR was performed using ntGHR2-R2 and SMART IV as primers, followed by a nested PGR using ntGHR2-R3 and SMART IV as primers.

For all the PCRs described in this section, the reaction was carried out with an initial denaturation at $94^{\circ} \mathrm{C}$ for 3 min, followed by $33-35$ cycles of $94{ }^{\circ} \mathrm{C}$ for $30 \mathrm{~s}$, $52-57^{\circ} \mathrm{C}$ for $30 \mathrm{~s}$ and $72{ }^{\circ} \mathrm{C}$ for $40 \mathrm{~s}$ to $1.5 \mathrm{~min}$. This was followed by a final step at $72{ }^{\circ} \mathrm{C}$ for a further period of $10 \mathrm{~min}$.

\section{Phylogenetic analysis of GHR sequences from various vertebrates}

Nucleotide and aa sequence editing, comparison and alignment were performed using Editseq and Megalign from the DNAstar package (DNASTAR, Madison, WI, USA). The multiple alignment software Clustal X (Thompson et al. 1997) was employed to construct the phylogenetic tree.

\section{Expression of sbGHR1 and sbGHR2 in seabream tissues}

RT-PCR was performed to assess the relative expression of sbGHR1 and sbGHR2 in various seabream tissues. First strand cDNA was synthesized from $3 \mu \mathrm{g}$ total RNA prepared from seabream tissues using Oligo- $\mathrm{dT}_{18}$ as primer and $\mathrm{MMLV}-\mathrm{H}^{-}$reverse transcriptase as enzyme (GeneSys, Borehamwood, Herts, England). Two pairs of gene specific primers, one pair specific for sbGHR1 (sbGHR1-F4 and sbGHR1-R3) and the other pair specific for sbGHR2 (sbGHR2-F5 and sbGHR2-R5), were used to amplify the two GHR transcripts from seabream tissues. The sbGHRl transcript gave an amplicon size of $938 \mathrm{bp}$ whereas the one for sbGHR2 was 443 bp. Negative control was also carried out on samples derived from mock reverse transcription reactions (i.e. no reverse transcriptase added) to rule out any possible contamination of RNA samples by genomic DNA. A pair of $\beta$-actin primers (sbActin-F and
sbActin-R) was used in parallel for normalization of the receptor expression level. After an initial denaturation at $94{ }^{\circ} \mathrm{C}$ for $2 \mathrm{~min}$, a 29 -cycle PCR was carried out at $94{ }^{\circ} \mathrm{C}$ for $30 \mathrm{~s}, 58^{\circ} \mathrm{C}$ for $30 \mathrm{~s}$ and $72{ }^{\circ} \mathrm{C}$ for either $1 \mathrm{~min}$ (for sbGHR1) or $30 \mathrm{~s}$ (for sbGHR2). This was followed by a final step at $72{ }^{\circ} \mathrm{C}$ for $10 \mathrm{~min}$. For the $\beta$-actin amplification, a 25-cycle PCR was used with an extension time of $30 \mathrm{~s}$, other conditions being identical. The cycle number adopted for each gene was initially determined by a validation test in each case in which the PCR was performed as described but terminated at different cycle numbers. A profile of the amount of PGR product generated at different cycle numbers was thus constructed and the cycle number finally chosen for the gene expression study was within the linear region of the amplification. This validation is important to ensure that the amount of PCR product reflects the amount of template in the original sample. The PCR products were then resolved on a 1.5\% agarose gel and stained with ethidium bromide. The band intensities, obtained by densitometric scanning, were analyzed using the Multi-Analyst software (Bio-Rad). Difference in intensity due to size difference of the two sbGHR amplicons has also been taken into account in the calculation of the relative expression values (Harms et al. 2000). The target band intensity was divided by the $\beta$-actin band intensity in each tissue for normalization.

\section{Functional expression of sbGHR1 and sbGHR2 in cultured eukaryotic cells}

The full-length receptor cDNAs cloned from seabream, viz. sbGHR 1 and sbGHR2, were functionally expressed in cultured Chinese hamster ovary (CHO-Kl) cells (American Type Culture Collection, Manassas, USA) and their biological activities were studied. $\mathrm{CHO}$ cells were transiently transfected with $50 \mathrm{ng}$ of a pcDNA3 1 vector (Invitrogen) carrying the entire coding region of sbGHR2 between the EcoR V and Not I sites. The sbGHR1 expression plasmid used has been reported previously (Tse et al. 2003). Briefly, $500 \mathrm{ng}$ of a luciferase reporter plasmid containing either the rat serine protease inhibitor (Spi $2 \cdot 1$ ) promoter in pGL2 vector (kindly provided by Dr Nils Billestrup at the Hagedorn Research Institute, Gentofte, Denmark), the rat $\beta$-casein promoter in pLucDSS or the human c-fos promoter in pFL711 (both kindly provided by Dr K L Yu at the Department of Zoology, University of Hong Kong) were co-transfected together with either one of the two GHR expression constructs. After $6 \mathrm{~h}$ of transfection, either recombinant seabream GH (sbGH) (Gropep, Adelaide, Australia), or purified GH (sGH), prolactin (sPRL) or somatolactin (sSL) from salmon (kindly provided by Dr. Penny Swanson at the Northwest Fisheries Science Center, Seattle, WA, USA) was added. The cells were incubated with the respective hormones for a further 
$20 \mathrm{~h}$. Afterwards, the cells were then washed and lysed for determination of luciferase activities. To detect the expression levels of the two receptors in the transfected CHO cells, total RNA of the control group in each case was extracted and used in the determination of receptor expression by RT-PCR using the same reaction conditions as described in the previous section for tissue distribution studies except that the number of PCR cycles was 28. A pair of gene specific primers for hamster $\beta$-actin, viz. CHO-Actin-F and CHO-Actin-R, was employed in parallel RT-PCR to normalize the gene expression results.

\section{Hormonal regulation of sbGHR1 and sbGHR2 gene expression in seabream liver in vivo}

Black seabream (body length: $22 \cdot 5 \pm 0.3 \mathrm{~cm}$, body weight $234 \cdot 5 \pm 11 \mathrm{~g}$ ) of both sexes were purchased from a local marine fish farm. Prior to the experiments fish were acclimatized for at least one month in the Marine Science Laboratory of the Chinese University of Hong Kong. Throughout the experiments, fish were kept in fully aerated seawater and were exposed to natural photoperiod at ambient temperature $\left(24-29^{\circ} \mathrm{C}\right)$ in May 2004. Fish were fed with commercially available fish pellet diet until satiety during the experimental period. Fish were injected with either cortisol $(5 \mu \mathrm{g} / \mathrm{g})$ (Sigma), $17 \beta$-estradiol $(2 \mu \mathrm{g} / \mathrm{g}) \quad$ (Sigma), testosterone $(2 \mu \mathrm{g} / \mathrm{g})$ (Sigma), sbGH $(1 \mu \mathrm{g} / \mathrm{g})$ (Gropep, Adelaide, Australia) or ipamorelin (10 ng/g) (NEOMPS SA, Strasbourg, France) intraperitoneally once daily for 4 days. Cortisol, estradiol and testosterone were dissolved in olive oil. Ipamorelin and sbGH were dissolved in $0.8 \%(\mathrm{w} / \mathrm{v})$ $\mathrm{NaCl}$ solution. The injections were performed at 10 a.m. every day and the tissues were collected from the fish at 3 p.m. on the day of the sacrifice. Olive oil or $0.8 \%$ (w/v) NaGl solution was used as the vehicle in the respective control groups. The fish were then killed by decapitation and tissues were stored in a $-70{ }^{\circ} \mathrm{C}$ freezer after being snap frozen. The expression levels of sbGHR 1 and sbGHR2 were assessed by RT-PGR using gene specific primers as detailed in the previous section on tissue distribution studies.

\section{Data analysis}

All data were expressed as mean values \pm S.E.M. $(n=6)$. Data were considered statistically significant at $P<0 \cdot 05$ using either one-way analysis of variance (ANOVA) or unpaired $t$-test.

\section{Results}

\section{Identification of GHR2 in teleosts}

When various fish GHR cDNA sequences were compared with the fugu genome on the NCBI database using the BLAST program, two genomic contigs with high scores and low expect values were identified (NCBI entry numbers: CAAB01001386, CAAB01001701), suggesting that the fugu genome probably contains two GHR genes. By adopting the same strategy, two genomic contigs with high scores and low expect values were also identified on the zebrafish genome (NCBI entry numbers: CR352327, BX530077). Interestingly, the deduced sequences of the two putative GHRs in fugu and zebrafish correspond to the two types of GHRs reported in various fish species in terms of their structural similarity. These observations are highly suggestive that two types of GHRs could be found concomitantly in a single fish species and the two clades of GHR sequences reported in various fish species so far only represent part of the whole picture. Based on the sequence information available on the two types of fish GHR, degenerate primers (Table 1) were designed for the amplification of both types of GHR from three teleost species.

A novel cDNA transcript showing sequence homology to our previously reported seabream GHR (sbGHR) (Tse et al. 2003) was isolated from the black seabream liver cDNA library. We name our previously reported sequence as sbGHR 1 and the newly identified sequence herein as sbGHR2. This new sequence contains $3875 \mathrm{bp}$ encompassing a $5^{\prime}$-UTR of $102 \mathrm{bp}$, a coding region of $1776 \mathrm{bp}$ and a 3'-UTR of $1997 \mathrm{bp}$ including the poly(A) tail. The coding region encodes a protein of 591 aa with a putative single transmembrane domain (Fig. 1). Several characteristic landmarks of GHR including the FGEFS motif, the Box 1 and Box 2 regions, and some of the conserved extracellular cysteine residues and intracellular tyrosine residues could be located. However, sbGHR1 and sbGHR2 possess features that are distinctly different from each other (Fig. 2). First, the number of extracellular cysteine residues is different. While sbGHR1 possesses 7 extracellular cysteine residues, sbGHR2 has only 5. Second, sbGHR1 contains 9 intracellular tyrosine residues but sbGHR2 contains only 6 . Moreover, the overall sequence identity between sbGHR1 and sbGHR2 is rather low, being $58 \cdot 1 \%$ at the nucleotide level and $33.7 \%$ at the aa level (Table 2).

The co-existence of two GHR subtypes in a single fish species was further demonstrated in two other teleost species. Both GHR1 and GHR2 cDNAs could be identified in Southern catfish and Nile tilapia. The Southern catfish GHRl (scGHRl) cDNA contains 1958 bp encoding for a protein of 602 aa whereas the Southern catfish GHR2 (scGHR2) cDNA contains $2300 \mathrm{bp}$ encoding for a protein of $553 \mathrm{aa}$. On the other hand, the Nile tilapia GHR1 (ntGHR1) cDNA contains $1908 \mathrm{bp}$ encoding for a protein of 635 aa whereas the Nile tilapia GHR2 (ntGHR2) cDNA contains $1725 \mathrm{bp}$ encoding for a protein of 574 aa. Similar to the 
gaacggccacctggtaaacaggaaggtctgagtggattgtggcagggagcagtgagccatcgtcaacctacatagttagttatggtcgccat ctagtgggtg ATG TAT CTT CTT CAG CTC GAC ACC ATG GCT GCC TCT CTC ACT CTA CTC TTC TTC CTA 159 $\begin{array}{llllllllllllllllllll}M & Y & L & L & Q & L & D & T & M & A & A & S & L & T & L & \text { L } & F & F & L & 19\end{array}$ TAC ATC TTC ACT TCT TCG GCG CTG GAA TCA ACG TCA GAG CAA GTC CAC CCT CAG AGG GAC CCA CAG 225 $\begin{array}{lllllllllllllllllllllll}Y & I & F & T & S & S & A & L & E & S & T & S & E & Q & V & H & P & Q & R & D & P & Q & 41\end{array}$ CTC ACG GGC TGT GTC TCT GCC AAC ATG GAg ACT TTC CGC TGC AGA TGg AAT GTC GGC ACT CTC CAG 291

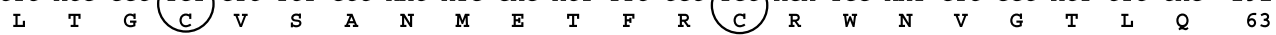
AAC CTC TCC AAG CCG GGA GAG CTC CGC TTA TTC TAC ATT AAC AAA TTA TCC CCA CTT GAT TCT CCT 357

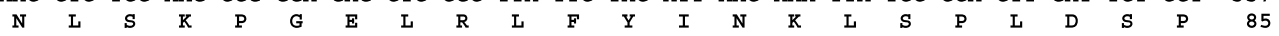
AAA GAG TGG ACA GAG TGT CCT CAC TAC AGC ACC GAC AGG CCA AAC GAg TGC TTC TTC AAT GAG AAC 423 $\begin{array}{lllllllllllllllll}K & E & W & T & E & C & P & H & Y & S & T & D & R & P & N & E & C \\ & F & F & N & E & N & 107\end{array}$ CAC ACA TCC ATC TGG ACA TTT TAC AGA GTC CAG CTT CGC TCG AGG GAC GAA TCC ACC GTC TAC GAC 489

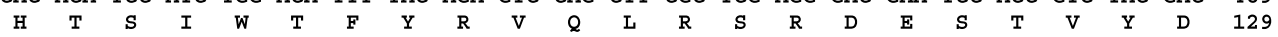
GAG AAC AAG TTC ACC GTC GAA GCC ATC GTG CAA CCA GAT CCT CCA TTT GAC CTG ACC TGG ACA ACA 555 $\begin{array}{lllllllllllllllllllllll}\mathbf{E} & \mathbf{N} & \mathrm{K} & \mathrm{F} & \mathrm{T} & \mathrm{V} & \mathbf{E} & \mathrm{A} & \mathrm{I} & \mathrm{V} & \mathrm{Q} & \mathrm{P} & \mathrm{D} & \mathrm{P} & \mathrm{P} & \mathrm{F} & \mathrm{D} & \mathrm{L} & \mathrm{T} & \mathrm{W} & \mathrm{T} & \mathrm{T} & 151\end{array}$ CTG AAT GAA AGT CTG AGC GGC GCT TAT TAT GAC GTC CTG CTG AGC TGG AAg CCG CCT CAG TCT GCA 621 $\begin{array}{lllllllllllllllllllllll}\mathrm{L} & \mathrm{N} & \mathrm{E} & \mathrm{S} & \mathrm{L} & \mathrm{S} & \mathrm{G} & \mathrm{A} & \mathrm{Y} & \mathrm{Y} & \mathrm{D} & \mathrm{V} & \mathrm{L} & \mathrm{L} & \mathrm{S} & \mathrm{W} & \mathrm{K} & \mathrm{P} & \mathrm{P} & \mathrm{Q} & \mathrm{S} & \mathrm{A} & 173\end{array}$ GAC GTG GCG ACG GGA TGg ATg ACG CTA CAg TAT GAg GTC CAg TAC CGC AGC GTC AGC TCT GAC CAG 687 $\begin{array}{lllllllllllllllllllllllll}\mathrm{D} & \mathrm{V} & \mathrm{A} & \mathrm{T} & \mathrm{G} & \mathrm{W} & \mathrm{M} & \mathrm{T} & \mathrm{L} & \mathrm{Q} & \mathrm{Y} & \mathrm{E} & \mathrm{V} & \mathcal{E} & \mathrm{Y} & \mathrm{R} & \mathrm{S} & \mathrm{V} & \mathrm{S} & \mathrm{S} & \mathrm{D} & Q & 195\end{array}$ TGG AAA GTG ATG GAT CCT GTG ATA AGC ACC CAT CGg TCT CTT TAC GGA CTT AAA CAC AAC GTC AAT 753 $\begin{array}{lllllllllllllllllllllll}\text { W } & K & V & M & D & P & V & I & S & T & H & R & S & L & Y & G & L & K & H & N & V & N & 217\end{array}$ CAC GAG GTT CGg GTC CGg TGC AGA ATG CTG GCT GGg AAA GAg TTT GGA GAA TTT AGC GAC TCC ATA 819

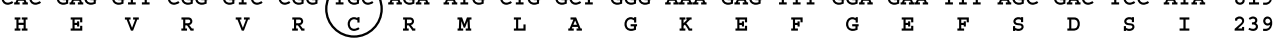
TTC ATC CAC ATC CCG GCG AAA GTG TCG AGT TTC CCA GTG GTG GCC CTC СTT CTC TTT GGA GCC TTG 885 $\begin{array}{lllllllllllllllllllllll}F & I & H & I & P & A & K & V & S & S & F & P & V & V & A & L & L & L & F & G & A & L & 261\end{array}$ TGT TTA GTG GCC ATC CTg ATg TTg GTC ATC ATA TCG CAg CAg GAA AAg tTg ATg TTT ATT CTT TTG 951

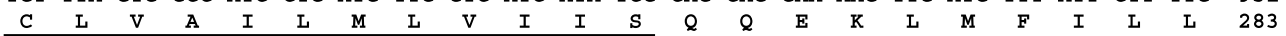
CCT CCT GTT CCG GGA CCC AAA ATA AGA GGA ATA GAC CCC GAA CTG CTC AAg GAA GgG AAg CTG AGA 1017

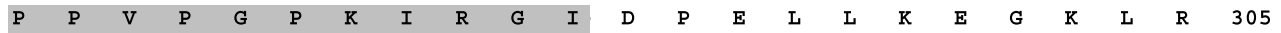
GAG TTG ACA TCC ATC CTG GGC GGC CCC CCT AAT CTG AGG CCG GAG CTG TAC AAC AAC GAC CCC TGG 1083 $\begin{array}{lllllllllllllllllllllllll}E & L & T & S & I & L & G & G & P & P & N & L & R & P & E & \text { L } & \text { Y } & \text { N } & \text { N } & \text { D } & P & \text { W } & 327\end{array}$ GTG GAA TTC ATC GAC CTG GAC ATC GAG GAG CAA GGC GAC AAG CTC ACA GAC CTG GAC ACG GAC TGT 1149 $\begin{array}{lllllllllllllllllllllll}\mathrm{V} & \mathrm{E} & \mathrm{F} & \mathrm{I} & \mathrm{D} & \mathrm{L} & \mathrm{D} & \mathrm{I} & \mathrm{E} & \mathrm{E} & \mathrm{Q} & \mathrm{G} & \mathrm{D} & \mathrm{K} & \mathrm{L} & \mathrm{T} & \mathrm{D} & \mathrm{L} & \mathrm{D} & \mathrm{T} & \mathrm{D} & \mathrm{C} & 349\end{array}$ CTC ATG CAC CGC TCC CTG TCC TCC AAC TGC ACT CCC ATC TCC ATT GGC TTC AGA GAT GAT GAT TCA 1215 $\begin{array}{llllllllllllllllllllllll}\mathrm{L} & \mathrm{M} & \mathrm{H} & \mathrm{R} & \mathrm{S} & \mathrm{L} & \mathrm{S} & \mathrm{S} & \mathrm{N} & \mathrm{C} & \mathrm{T} & \mathrm{P} & \mathrm{I} & \mathrm{S} & \mathrm{I} & \mathrm{G} & \mathrm{F} & \mathrm{R} & \mathrm{D} & \mathrm{D} & \mathrm{D} & \mathrm{S} & 371\end{array}$ GGT CGG GCC AGC TGC TGC GAC CCA GAT CTC CCC AGC GAC CCT GAA GCA TCG CCT TTC CAT CCT CTC 1281 $\begin{array}{lllllllllllllllllllllllll}\text { G } & R & A & S & C & C & D & P & D & \text { L } & \text { P } & \text { S } & \text { D } & \text { P } & \text { E } & \text { A } & \text { S } & \text { P } & \text { F } & \text { H } & \text { P } & \text { L } & 393\end{array}$ ATC CCA AAT CAG ACC CTC AGT AAG GAA GTG TCG TGC CAG ACC GCC AGC GAG CCA AGC TCC CCA GTC 1347 $\begin{array}{lllllllllllllllllllllllll}I & P & N & Q & T & L & S & K & E & V & S & C & \& & T & A & S & E & P & S & S & P & V & 415\end{array}$ CAG AGC CCC GCC TCT GGA GAg CCT CCT TTT GCA GCA CCG GGC AGA GAg GCT ATg TAC ACC CAG GTG 1413 $\begin{array}{lllllllllllllllllllllll}Q & S & P & A & S & G & E & P & P & F & A & A & P & G & R & E & A & M & Y & T & Q & V & 437\end{array}$ AGT GAG GTG AGA TCG TCT GGC AAG GTG CTG CTG TCG CCT GAG GAA CAG ACC GAG GTG GAG CAA ACC 1479 $\begin{array}{lllllllllllllllllllllll}\mathrm{S} & \mathrm{E} & \mathrm{V} & \mathrm{R} & \mathrm{S} & \mathrm{S} & \mathrm{G} & \mathrm{K} & \mathrm{V} & \mathrm{L} & \mathrm{L} & \mathrm{S} & \mathrm{P} & \mathrm{E} & \mathrm{E} & \boldsymbol{Q} & \mathrm{T} & \mathrm{E} & \mathrm{V} & \mathrm{E} & \boldsymbol{Q} & \mathrm{T} & 459\end{array}$ ACT GGG AAA GAC ACG GAG AAA GAC ATC ATG GCG GAG AAG GAG AAA GCA AAg AAA GAG TTG CAG CTC 1545 $\begin{array}{lllllllllllllllllllllll}T & G & K & D & T & E & K & D & I & M & A & E & K & E & K & A & K & K & E & L & Q & L & 481\end{array}$ CTG GTG GTG AAT GCA GAT CAg GGg GGT TAC ACC TCA GAG CTC AAC GCA GgG AAA ATG AGC CCA AGA 1611 $\begin{array}{lllllllllllllllllllllll}\mathrm{L} & \mathrm{V} & \mathrm{V} & \mathrm{N} & \mathrm{A} & \mathrm{D} & \mathrm{Q} & \mathrm{G} & \mathrm{G} & \mathrm{Y} & \mathrm{T} & \mathrm{S} & \mathrm{E} & \mathrm{L} & \mathrm{N} & \mathrm{A} & \mathrm{G} & \mathrm{K} & \mathrm{M} & \mathrm{S} & \mathrm{P} & \mathrm{R} & 503\end{array}$ TTG TCC ATA GGA GAT CAG AGT GAA CCC TGC CTG ACA GGA GAC TTG AGT CCT TTG CCA CCC GCA TCG 1677 $\begin{array}{lllllllllllllllllllllll}\text { L } & S & I & G & D & Q & S & E & P & C & \text { L } & \text { T } & \text { G } & \text { D } & \text { L } & \text { S } & \text { P } & \text { L } & \text { P } & \text { P } & \text { A } & \text { S } & 525\end{array}$ CCT TAC CAT GAA TCG GAT ACT GCC GCC GTG TCC CCT CTT CCC CCT GCT CCT GTC TAC ACC GTG GTA 1743 $\begin{array}{lllllllllllllllllllllll}P & Y & H & E & S & D & T & A & A & V & S & P & \text { L } & \text { P } & \text { P } & \text { A } & \text { P } & \text { V } & \text { Y } & \text { T } & \text { V } & \text { V } & 547\end{array}$ GAG GGT GTT GAC AGg CAg AAC AGC CTC TTA CTC ACA CCA AAC TCA ACA CCT GCC CCC CAG CTG ATA 1809 $\begin{array}{lllllllllllllllllllllll}\mathbf{E} & \mathrm{G} & \mathrm{V} & \mathrm{D} & \mathrm{R} & \mathrm{Q} & \mathrm{N} & \mathrm{S} & \mathrm{L} & \mathrm{L} & \mathrm{L} & \mathrm{T} & \mathrm{P} & \mathrm{N} & \mathrm{S} & \mathrm{T} & \mathrm{P} & \mathrm{A} & \mathrm{P} & \mathrm{Q} & \mathrm{L} & \mathrm{I} & 569\end{array}$ ATC CCC AAg ACC ATG CCA ACA CCA GGC GGC TAC CTG ACC CCT GAC CTT CTG GGA AGC ATC ACA CCA 1875

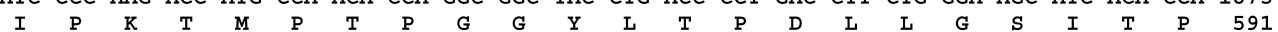
TAG atcagcagcgaatggtgcatggttaggactggtcaatcaaaggagaacagtcttgggtattgacttttgagggcccegtggttgagcgtcgaatgtcagctctcctgaaatagttttt 1997

ggggggaggggcatctgtgcctgtcctgccaccgcctctgcatctggcctcccactgctccctcagacacggccgtaacatcgagtttggtatgagggaggacgagcgcacaaggatgtttt 2119 taactgcaatagaggaaaaggaaccttccaaagggaaataccacaaaccagttgctggaaatgttcttaaaaacaggtttacactttctaaaggtgcgccatgcaggaaaacaacgtatcga 2242 ctcataaaaaagtaatccetctctgtcatccttataacccactagaagtgtgtggcactgtctacatgtgcagagacccttctctctgcatgggtttctaatttgtatagcatttgcagggttaggg 2372 gcatccaggtcaacagaacagtgcaagatgtgaagtcggactcagtttccttcgctccatctgtctctttcctctgctccgggetgttatggtgtaaagagggcagcaggttcgtgtgectgttc 2498 gtttgactgagggtggtgctgagctacactcagagcagagcggccaacagcagacaggataaagcatgcacttcagetgcattccegtgacaaaacccagagggttatgcagaagtttgag 2619 cgtgttgattcatagagcattcc gacatttatgtatgtgctttgttctctttaacgccactccttctcttcattaacatctagcttgccagatcaccaccgetccetctctctctctctcagattctgtcat 2753 tgaggagggggetcttttaaaaaattggacagaagaattcagcaatcatagtgcattacttgttttggataacgtactgacaagcaaatgccatcatgtattcatatgtagtcacgtttctgttcagt 2882 tgatgaatttcactctcttttaagctctggcttggectccatcaactctttagaaaatcatctgtctcctgagctgcgaaatgctccagtttctcaccatcttgtcgctcattttctgtctgctgttaagtg 3015 cttcgagcgaaaaggctgaagagctgcgtcgtgctgcagagttgttgttaattccetgtggttcgtcactacaggtaatcattttacattgtaagtagtcatttcattcagtgttaaaacaagaatat 3144 tgacttgtgcagctttaaataagggcacattaaattgcatttgtaaattgttggatgcttcttttttttttttttttacattttgtacatatcaaaagctctgtcagataaaatcaggtcatttgtaaatgac 3280 aaactgtgcgaaaaaatgcctgtcaacgtaaaattatcacttgctgtcttttacgaagtcagcaattttagctttccagaagttccattagtattctttttcttcagtcctatttgagctttgagaccaa 3412 tattagtgttacttcctcaataagtaatccattgctctattgtaatactcgatcttacagcetgggtttatatatcatgaatatcatgatattaccaacacatgaactccagagtttaaaagtaaggcatg 3543 agttgtttgtaaaagtggcgactggagcagatgcttatcgtatttgacgccattgcgctcttcatttatgtttcaagaactgtgaaacgttcgtagagctgaacgaactaatctgctctgtcagcat 3671 gtgtttaccagtgcatgcgatgtacaagttttgttttcatttggtttctgatatacagcgcactgaatgccagtgtagttgggggacacatggtcatcagtgttggatttgtaaagttgcattgcat 3801 tttgactgttcataagtgattcacaaataaacagactttcataaatctgaaaaaaaaaaaaaaaaaaaaaaa 


\begin{tabular}{|c|c|c|}
\hline $\begin{array}{l}\text { sbGHR1 } \\
\text { sbGHR2 }\end{array}$ & $\begin{array}{l}\text { MSVSSSSSSSSSTSNLLLLLLVSSLDWLSTRGSALAMDHMTSSAPVGPHFTECVSREQETFRCW } \\
\text { MYLLQLDTMAASLT--LLFFLYIFT-----SSALESTSEQVHPQRDPQLTGCVSANMETFRCR }\end{array}$ & $\begin{array}{l}65 \\
56\end{array}$ \\
\hline SbGHR1 & WSPGGFHNLSSPGALRVFYLKKDSP - - TSEWKECPEYSHLKR - ECFFDVNHT SVWVPYCMQLRG & 126 \\
\hline SbGHR2 & WNVGTLQNLSKPGELRLFYINKLSPLDSPKEWTECPHYSTDRPNECFFNENHTSIWTFYRVQLRS & 121 \\
\hline SbGHR1 & QNNVTYLDEDYCFTVENIVRPDPPVSLNWTLLNISPSGLSYDVMVTWEPPP SADVGAGWMRIEYE & 191 \\
\hline SbGHR2 & RDESTVYDENK -FTVEAIVQPDPPFDLTWTTLNESLSGAYYDVLLSWKPPQSADVATGWMTLQYE & 185 \\
\hline SbGHR1 & IQYTERNTSNWEALEMQPHTQQTIYGLQIGKEYEVHIRCRMQAFVKFGEFSPSVFIQVTEIPSQD & 256 \\
\hline SbGHR2 & VQYRSVSSDQWKVMDPVISTHRSLYGLKHNVNHEVRVRCRMLAGKEEGEFSDSIFIH - - IPAKV & 247 \\
\hline SbGHR1 & SNVPFKLALIFGVLGILILILLIGISQQPRLMMILLPPVPAPKIKGIDPELLKKGKLDELNFILS & 321 \\
\hline sbGHR2 & SSFPVVALLLFGALCLVAILMLVIISQQEKLMFILLPPVPGPKIRGIDPELLKEGKLRELTSIL - & 307 \\
\hline $\begin{array}{l}\text { SbGHR1 } \\
\text { SbGHR2 }\end{array}$ & $\begin{array}{l}\text { GGGMGGLSTYAPDFYQDEPWVEF IEVDAEDADAAEKEENQGSDTQRLLDLPQPVSHHMNIGCAN - } \\
--- \text { - GGP PNLRPELYNNDPWVEF IDLDIEEQG - -- - DKLTDLDTDCLMH - - - - RSLSSNCTPI }\end{array}$ & $\begin{array}{l}385 \\
362\end{array}$ \\
\hline SbGHR1 & AVSFPDDDSGRASCYYDPDLHDQDTLMLMATLLPGQPEAGEDSFDVV - ESAPVIERSERPLMQTQT & 449 \\
\hline SbGHR2 & SIGFRDDDSGRASCCDPDLPSDPEASPFHPLIPNQTLSKEVSCQTASEPSSPVQSPASGEPPFAA & 425 \\
\hline SbGHR1 & GGPQTWVNTDFYYAQVSNVMPSGGVVLSPGQQLRLQESTSATEDEAQKKGKGSEDSEVKAQKELQF & 514 \\
\hline SbGHR2 & PGREA - - - - MYTQVVSEVRSSGKVLLSPEEQTEVEQTTGKDTEKDIMAEKE - - - - -KAKKELQ̄ - & 479 \\
\hline sbGHR1 & QLLVVDPEGSGȲTTESNARQISTPPSTPMPGSGY్QTIHPQPVETKPAATAENNQSPYYILPDSPQS & 579 \\
\hline SbGHR2 & -LLVVNADQGGYTSELNAGKMS - - - - PRLSIGDQSEPCLTGDLSPLPPA - - - SPYHESDTAAV & 535 \\
\hline & FFAPVADYTVVQEVDSQHSLLLNPPPRQSPPPCLPHHPAKALPAMPVGYYVTPDLLGNLSP & 640 \\
\hline SbGHR2 & SPLPPAPVYTVVEGVDRQNSLLLTPNSTPAPQLIIP- - - KTMPT - PGGYLTPDLLGSITP & \\
\hline
\end{tabular}

Figure 2 Alignment of sbGHR1 and sbGHR2 aa sequence. The conserved cysteine residues in the extracellular domain and conserved tyrosine residues in the intracellular domain are shaded in dark. The FGEFS motif is boxed by an open rectangle. The transmembrane domain is underlined with two solid lines. The Box 1 and Box 2 regions are shaded in gray. Gaps are introduced for maximal similarity.

sbGHRs, characteristic motifs of GHR could also be identified in the scGHRs and ntGHRs. Sequence information of sbGHR2, scGHR1, scGHR2, ntGHR1 and ntGHR2 can be viewed in the NCBI GenBank database with accession numbers AY662334, AY336104, AY973231, AY973232 and AY973233 respectively.

Phylogenetic analysis of GHRs from various vertebrates indicated that the fish GHRs could be clustered into two clades (Fig. 3). The GHR1 clade encompasses the sequences previously reported in a number of fish species including the goldfish (Lee et al. 2001), grass carp (GenBank accession number AY283778), black seabream (Tse et al. 2003), gilthead seabream (CalduchGiner et al. 2003), Mozambique tilapia (Kajimura et al. 2004), halibut (GenBank accession number AB058418), turbot (Calduch-Giner et al. 2001) and eel (isoform 1: GenBank accession number AB180476; isoform 2: GenBank accession number AB180477), as well as the Southern catfish and Nile tilapia GHR1 sequences obtained in the present study. The GHRs within this clade are structurally more homologous to GHRs found in the non-teleost vertebrates. The GHR2 clade, which is unique to teleosts, encompasses the previously reported GHR sequences in salmonid species (Fukada et al. 2004, Very et al. 2005), and gilthead seabream (Saera-Vila et al. 2005) as well as the black seabream, Southern catfish and Nile tilapia GHR2 sequences obtained in the present study. Structural homology among all the so far known members of the fish GHR2 clade is shown in Fig. 4. They exhibit higher aa sequence similarity to each other (Table 3).

Figure 1 Nucleotide and deduced aa sequences of the sbGHR2. Nucleotides (upper sequence) and aa (lower sequence) are numbered on the right hand side. The following are highlighted: conserved cysteine residues in the extracellular domain (circled), FGEFS motif (underlined with a dotted line), transmembrane domain (underlined with two solid lines), Box 1 and Box 2 regions (boxed in shaded rectangles), and the stop codon (marked with an asterisk). 
Table 2 Amino acid similarity between the fish GHR1s and GHR2s

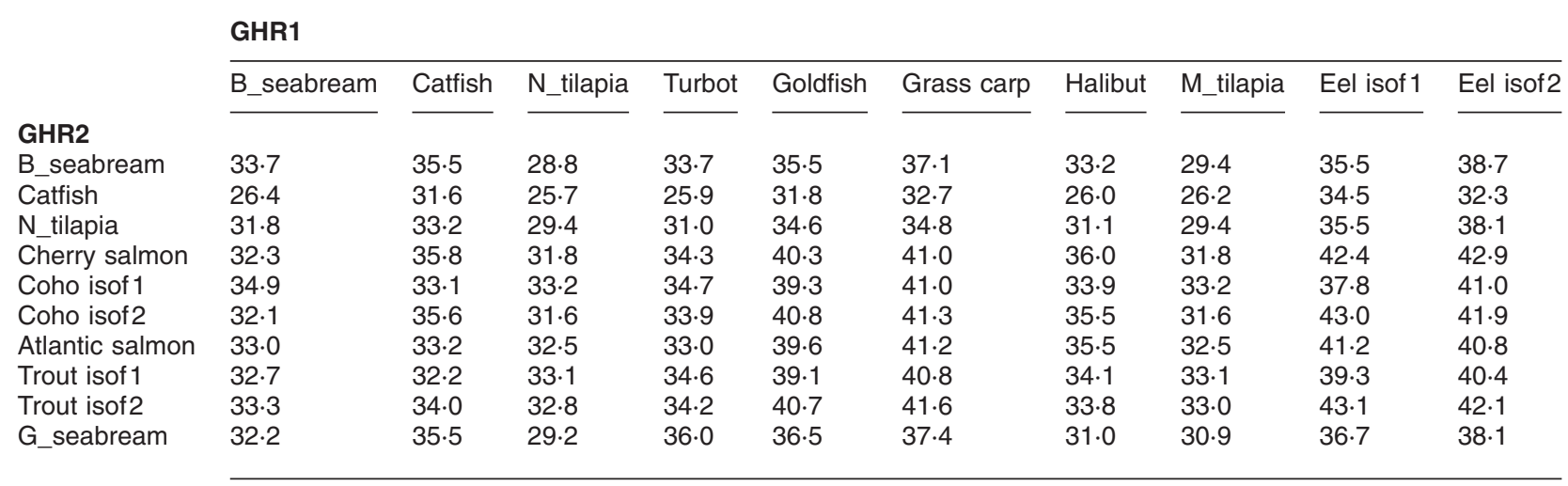

The Clustal method of the DNASTAR software was employed to compare the fish GHR1 and GHR2 aa sequences. Data are expressed as percentage aa identity. B_seabream, black seabream GHR; Trout isof 1, rainbow trout GHR isoform 1; isof2, isoform 2; Coho isof 1, coho salmon GHR isoform 1; isof2, isoform 2; M_tilapia, Mozambique tilapia; N_tilapia, Nile tilapia.

\section{Different expression patterns of sbGHR1 and sbGHR2 in seabream tissues}

Similar to that of sbGHR1, expression of sbGHR2 could be detected in all the seabream tissues tested, albeit at different levels. The expression level of sbGHR2 appeared to be higher than sbGHR1 (Fig. 5). The highest expression of sbGHR2 was found in the liver, followed by muscle and pituitary. In the gonad, kidney, muscle, pituitary and spleen, the expression of sbGHR2 was found to be significantly higher than that of sbGHR1.

\section{Functional expression of sbGHR2 in CHO-K1 cells}

As shown in Fig. 6, when sbGHR2 was expressed in cultured CHO-K1 cells, receptor activation by sbGH could stimulate both the Spi $2 \cdot 1$ promoter (Fig. 6A) and the $\beta$-casein promoter (Fig. 6B) but not the c-fos promoter (Fig. 6C), while sbGHRl could stimulate all the three promoters. A much bigger stimulation of promoter activities by sbGHR1 than sbGHR2 was also observed. This could not be attributed to the difference in the expression levels of the two receptors in the transfected cells since determination of receptor levels in the cultured cells by RT-PCR (Fig. 6D) indicated that the two receptors had very similar expression levels in the transfected cells. Ligand specificity of receptor interaction was tested by stimulating the receptor transfected cells with sGH, salmon prolactin (sPRL) or salmon somatolactin (sSL). It was shown that either sbGH or sGH could stimulate the Spi $2 \cdot 1$ promoter (Fig. $7 \mathrm{~A}$ ), the $\beta$-casein promoter (Fig. 7B) and the c-fos promoter (Fig. 7C) in CHO cells expressing sbGHR1. On the other hand in CHO cells expressing sbGHR2, the promoter activities could be stimulated by sbGH for the Spi $2 \cdot 1$ promoter (Fig. 7A), and by sbGH or $\mathrm{sGH}$ for the $\beta$-casein promoter (Fig. $7 \mathrm{~B}$ ). In contrast to the sbGHR1, no stimulation of the c-fos promoter could be observed for the sbGHR2 (Fig. 7C). Neither sPRL nor sSL could trigger any detectable activation of the Spi $2 \cdot 1$

Figure 3 Phylogenetic analysis of aa sequences of GHRs from different vertebrates. The default settings of the ClustalX protein alignment program was employed using the goldfish PRLR (NCBI accession no. AF144012) as the outgroup, and visualized by the NJPLOT program. The values represent bootstrap scores out of 1000 trials, indicating the credibility of each branch. The two fish GHR clades are named as GHR1 and GHR2. The GHR sequences used in the present study are: Southern catfish (Silurus meridionalis), AY336104; goldfish (Carassius auratus), AF293417; grass carp (Ctenopharyngodon idella), AY283778; black seabream (Acanthopagrus schlegeli), AF502071, bastard halibut (Paralichthys olivaceus), AB058418; cherry salmon (Oncorhynchus masou), AB071216; gilthead seabream (Sparus aurata), AF438176; turbot (Scophthalmus maximus), AF352396; coho salmon (Oncorhynchus kisutch) isoform 1, AF403539; coho salmon isoform 2, AF403540; Japanese eel (Anguilla japonica) isoform 1, AB180476; Japanese eel isoform 2, AB180477; Mozambique tilapia (Oreochromis mossambicus), AB115179; Nile tilapia (Oreochromis niloticus), AY973233; black seabream, AY662334; Southern catfish, AY973231; rainbow trout (Oncorhynchus mykiss) isoform 1, AY861675; rainbow trout isoform 2, AY751531; Atlantic salmon (Salmo salar), AY462105; gilthead seabream, AY573601; domestic pigeon (Columba livia), D84308; rabbit (Oryctolagus cuniculus), AF015252; Bolivian squirrel monkey (Saimiri boliviensis), AF339061; soft-shelled turtle (Pelodiscus sinensis japonicus), AF211173; Norway rat (Rattus norvegicus), NM_017094; olive baboon (Papio anubis), AF150751; gray short-tailed opossum (Monodelphis domestica), AF238491; house mouse (Mus musculus), NM_010284; human (Homo sapiens), NM_000163; silver-gray brushtail opossum (Trichosurus vulpecula), AF467545; domestic guinea pig (Cavia porcellus), AF247665; African clawed frog (Xenopus laevis), AF193799; cow (Bos Taurus), NM_176608; dog (Canis familiaris), AF133835; pig (Sus scrofa), X54429; sheep (Ovis aries), M82912; chicken (Gallus gallus), NM_001001293; Rhesus monkey (Macaca mulatta), U84589; giant panda (Ailuropoda melanoleuca), AF395535. 


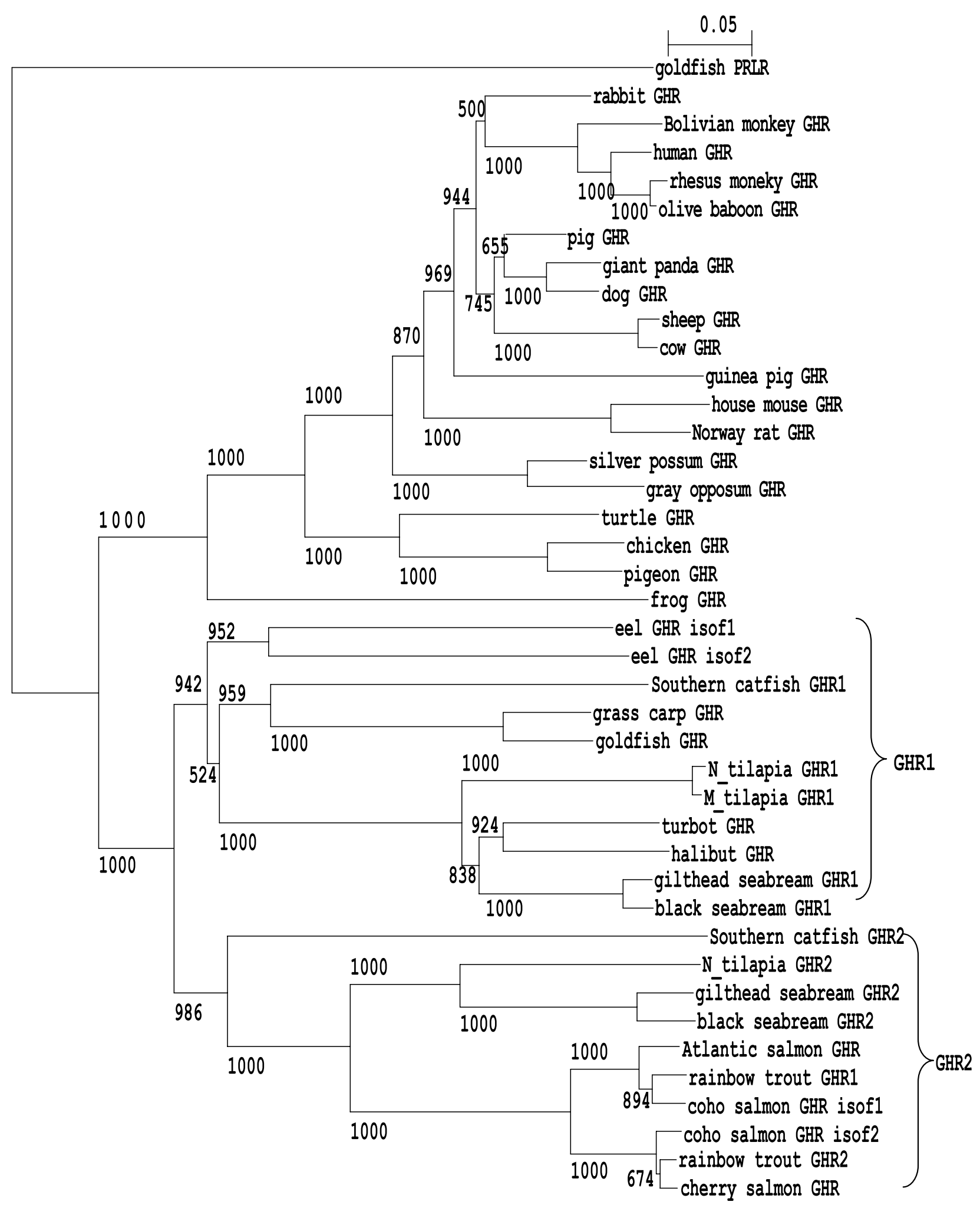




B_seabream
G_seabream
Catfish
Tilapia
Coho 1
Coho 2
Cherry
Trout 1
Trout 2
A_salmon

G-seabream Gatfish Catfish Tilapia Coho 1 Coho 2 Cherry Trout 1 Trout 2

A salmon

B_Seabream G-seabream Cátfish Tilapia Coho 1 Coho 2

Cherry

Cherry

Trout 1

A_salmon

B_seabream Catfish

Tilapia

Tilapia

Coho 1

Cherry

Trout 1

Trout 2

A salmon

B_seabream _seabream Catfish Tilapia Coho 1 Coho 2 Cherry

Trout 1

Trout 1 A_salmon

B_seabream G seabrean Cátfish Tillapia Tilapia Coho 1 oho 2 Cherry Trout 1 Trout 2

A_salmon

B_seabream -seabrear Catfish Tilapia Coho 1 Coho 2 Cherry

Trout 1

Trout 1

Arout 2

B seabream G seabream Cátfish Tilapia Tilapia Coho 1 Coho 2 Cherry Trout 1 Trout 2 A_salmon

MYLLQLDTMAASLTLLFFLY-IFTSSALES-TSEQVHPQRDPQLTG M-------AAALTLLFCLY-I LTS SALES-ASEQVHPQRDPHLT $M-------$ GIHISFICLFLVVAVSAEDVQASVQAQNKS L P FLI M------APTVTMLLF-VLHILTALVLQS-ASEPVLSERRPHLT, M------A I SHI LF ICLVLI LPVLSQEP PTSKQALFQIRPQI M-------ATSRILF ICLLLI LTVVSQEP PTSEQALPQIRPQIT M------ATSY I LF ICLLLI LTVVSQEP PTSEQALPQIRPQI T

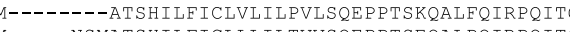
M-----NSMATSH I LF ICLLLI LTVVSQEPPTSEQALPQIRPQIT M----A A SHILFICLLLILAVLSQEPPTSKQALSQIRPQI

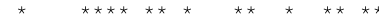
VSANMETFRCR WNVGTLQNLSKPGELRLFYINK 78 SANMETF SPDMMTF VSHDMNTFR SHDMNTF SHDMNTF S HDMNTF SHDMNTFR SHDMNTF CRMVTLOSKPGELRLFYINK 78 WNVTLNLSKPGELRLFYINK NGSFNLTEPGDLRLFYMHK WNVGVFONLTEPRDLRI FYYIN WNVGT 2 TITRRDRIFYYN 72

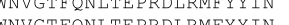
年 WNVGVFQNLTEPRDLRIFYYIN WNVGTEQNLTEPGDLRMFYYIN WNVGVFQNLTEPRDLRIFYYIN

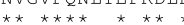

LSPLDSPKEWTECPHYSTDRPNECFFNENHTS IWTFYRVQLRSRDESTVYDENKFTVEAIVQPDPPFDLTWTTLNESLSG LSPLDP PKEWTECPHYS I DRPNECF FNKNHTSVWT PYKVQLRSRDESTLYDENTFTVDAIVQPDP PVDLTWTTLNESLSG ETKNDC--KWQECPSYSSAVENECY FDANH TAVWFQYAIQLRSRTND-VYDEMYFS LEE IVFPDPPKVLNWTLLSLGPTG VPPPLSSKNWTECPHYSTETPNECFFDQNHTS IWTYYNVQL RSRDET ILYDEKGFFVNDIVOPDPPVSLNWTLLNVSSTG -DRNISPKEWGECPRY-ADRTNECFFNESYTKVWMTYSVQLRS GDQDI LYXEVIFTVEDIVEPDPPIALNWT LLNVGLTG
-NKNISPKEWSECPNYMADRIDECFFNESYTKVWITYSVQLRSGDQDNLYDEVIFTVEDIVEPDPPIALNWTLLNVGLTG -NKNISPKEWSECPNYMADRIDECFFNESYTKVWITYSVQLRSGDQDNLYDEVIFTVEDIVEPDPPIALNWTLLNVGLTG -NKNIS PKEWSE CPNYMADRI DECEFNESYTKVWITYSVQLRS GDQDNLY DEVI FTVEEIVEPDPP IALNWTLLNVGLTG -DRNISPKEWGECPRYV-DRTNECFFNESYTKVWITYSVQLRSGDQDI LYDEVIFTVEDIVEPDPPIALNWTLLNVGLTG -NKNISPKEWSECPNYMADRIDECFFNESYTKVWITYSVQLRSGDQDNLYDEVIFTVEDIVEPDPPIALNWTLLNVGLTG -DKNISPKEWDECPHY-ADRTDECFFNESYTKVWMTYSVQLRSGDQDI LYDEVIFTVEDIVEPDPPIALNWTLLNVGLTG

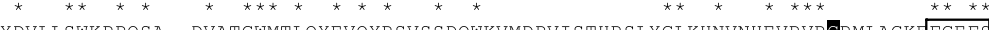
AYYDVLLSWKPPQSA--DVATGWMTLQYEVQYRSVSSDQWKVMDPVISTHRSLYGLKHNVNHEVRVRCRMLAGKF FGEF: 236 TYYDI I LSWKP PQSA--DVAMGWMT LQYEVQYRSAS SDLWHAVEPVTVTQRSLFGLKHNVNHEVRVRCKMLAGKEFGEF: 228 LFCDVMVSWD I PS SAADS VKI GWMT LWHETQYRERGS DEWKS LDNGKDTQAN I YGLRSNTEYEVRVRSK-MRGYNFGDF 227 IHYD I LLSWKP P PSS - -DVETGWMKLQYEVQHRDNSS SVWEMVDPVSSTQCS LYGLQTN INHEIRVRCKMLGGKAFGEF 229 SHFD IMLSWEP PHSA--DVSMGWMT LQYEVQYREVNST LWRTVDLEKGMQRS LYGLRSNT DNEVRVRCKTLASRNFGEF: 228 SHFDIMVSWEPPHSA--DVSMGWMTLQYEVQYREVNSTLWRMVNLEKGRQRS LYGLRTNTDNEVRVRCKTLASRNFGEF月 229 SHFDIMVSWEPPHSA--DVSMGWMTLOYEVOYREVNST LWRMVNLEKGRORS LYGLRTNTDHEVRVRCKTLASRNFGEFS 229 SHFDIML SWEPPHSA--DVSMGWMT LOYEVQYREVNSTLWRTVDLDKGMQRS LYGLRTNTDNEVRVRCKTLASRNFGEF: 228 SHFDIMVSWEP PHSA--DVSMGWMTLQYEVQYREVNST LWRMVNLEKGRQRS LYGLRTNTDHEVRVRCKTLASRNFGEF: 232 SHFDIMLSWEPPHSA--DVSMGWMT LQYEVQYREVNSTLWRTVDLEKGMQRS LYGLRTNT DNEVRVRCKTLASRNEGEFG

$$
\text { ** }
$$$$
\text { (1) }
$$$$
\text { PPVP }
$$
$* * * * *{ }^{*}$ DSIFIHI PAKVSS F PVVALLLFGALCLVAILMLVI ISQQEKLMF ILLPPVPGPKIRGIDPELLKEGKLRELTS ILGGP PN DS I FVH I PAKVSS S PVVALL LF GA LCLVA I LMLVI I SQQEKLMF I L LPPVPGPKIRG IDPE L LKKGKLRE LTS I LGGPPN

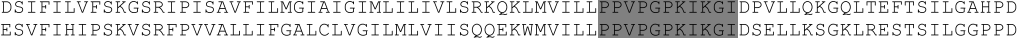
DSIFIHIPTKESR PVTVLLVFAALG AVILMLVIYSOQRKMVI LLP PIPGPKIKGIDPELFKKGKLAELTSILGGIPD DPIVIHIPTKESRFPVTVLLVFAALGLAVILILVIYSOQOKLMMI LLPP I PGPKIKGIDPELFKKGKLAELTSILGDHPD DPIVIHIPTKESRFPVTVLLVFALGLAVILILVI SQQQKLMMI LLPP I PGP IKGIDPE LFKKGKLAE LTS I LGDHPD

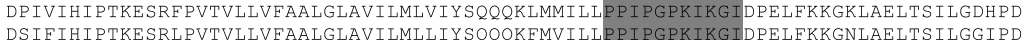
DS I F I I I PTKESRL PVTVLLVF AALGLAVI LMLL IY SQQQKFMV I LLPP I PGPK IKG I DPE LFKKGNLAE LTS I LGG I PD DP IVI I PTKESRFPVTVLLVFAALGLAVI I I LVIY SQQQKLMMI LLPP I PGPK I KGIDPEL FKKGKLAELTS I LGDHPD DS I F I H I TRESRLPVTVLLVEAALGLAVI LMLVVYSQQQKLMVI LLPP I PGPK I KG IDPE LLKKGKLAE LTS I LGG I PD $\star \star \star \star *$ $\star * \star * * * * * \star * * * * * * * *$

RPEIYNNDPNVE LRPELYNNDPWVEF IDLDIEEQGDKLTDLDTDCLMHRS LSSNCTPISIGFRDDDSGRASCCDPDLPSDPEASPFHP- - I I LRPELYNNDPWVEFIDLDIEEQSDKLTDLDTDCLMHRS LSSNCT PVSIGFRDDDSGRASCCDPDLPSDPEASPFHP--LI LRPELYSNDPWVEF IQVDIDEPTEMMEGLDTPLLFSESRVS DSPPTSSGF LDDDSGRASCCDPDLSDHDHHGAHHPSTLI
LRPELYNSDPWVEFIDLDIEEQSDRVTDLDTDCLMNHLSSNCSPLSLGFRDDDSGRASCCDPDLPCDPEPSPFLP--LV LRPDLYSDDPh LRPELYGEDPWVEF IELDMEEPNDRLTELDTQCLMDRSPSS DCPPLT I GFGDDDSGRASCCDPDLP-EPEAFPFHP--LL LRPELYGEDPWVEF IEL DMEEPNDRLTELDTOCLMDRSPSSDCPPLT I GFGDDDSGRASCCDPDLP-EPEAFPFHP- - IL LRPDLYSDDPWVEF IELDMEFPNDRL TVI DTHCLMDHCASSDCPPITIGERDDSGRASCCDPDLP-DPEA-PFHS-- II LRPDLYSD LRPELYCEDPWVEFIELDMEE HTHCLMDHCASSDCPPITIGFRDDDSGRASCCDPDLP-DPEA-PFHS--LL PNDRLTELDTQCLMDRTPSS DCP PLT I GFGDDDSGRASCCDPDLP-EPEAFP------
PNNRLTVLDTOCLMDHCASSDCPPIT I GFRDDDSGRASCCDPDLP-DPEASPFHS--I $\Delta$

$$
\text { ********* } *
$$

PNQTLSKEVSCQTASEPSSPVQSPASGEPPFAAPGREAMYTQVSEVRSSGKVLLSPEEQTEVEOTTGKDTEKDIMAEKEK PNQTLSKEVSCQTASEPSSPVQSPASGEPPFAALGREAMYTQVSEVRS SGKVLLSPEEQTEVEKTTGKDTEKDIMAEKEK PNANLGAQQSVVSHAQ----------EPAW----QNS I YSQVAEVMPCGETLLCPEQNVT DDCNIQDKT SEY----- K PNLALSQETLCAATSEPSSPIQSCNSGELPSFVTGRDTLYTQVTEVRSSGKVLLLPEEQTEREKMSSKEKEDEIVVEKEK PNTSHALEPSCLASTKASSPVOTPTTEDSPWAAPGREDIYTOVNEVGPTGEVLLTNEEORNVEENSEKDEKEN---EKEK SNTSPS LVPSG-ASTEASSPVQTPTTGMI LWAVPGREDLYTOVSEVRPTGEVLLMPEEOSKVEKDAEEKAKEEM--GKKK SNTSPSLEPSG-ASTEASSPVOTPTTGMTLWAVPGREDLYTQVSEVRPSGEVLLMPEEOSKVEKDAEEKAKEGK--EKEK SNTSPSLEPSG-ASTEAS SPVQTPTTGMTLWAVPGREDLYTQVSEVRP SGEVLLMPEEQSKVEKDAEEKAKEGK--EKEK
PNTSRALEPSCLASTKAS SPVQTPTTEDS PWAS PGREDLYTQVNEVRLTGEVLLTHEEQRNVDENSEKDEKE---KEKEK PNTSRALEPSCLASTKASS PVQTPTTEDS PWAS PGREDLYTQVNEVRLTGEVLLTHEEQRNVDENSEKDEKE---KEKEK
SNTS PSLEPSG-ASTEAS PVQTPTTGMTLWAVPGREDLYTQVSEVRPTGEVLLMPEEQSKVEKDAEEKAKEG--KEKEK SNTSCALEPSCLASTKASS PVQTPTTEDS PWAAPGREDLYTQVNEVRLTGEVLLTPEEQRKVEENAEKDAKE---KEKEK

AKKE LQLLVVNADQGGYTSELNAGKMS PRLS I GDQSEPCLTGDLSPLPPASPYHE- - -

E-* EKRPWLMVTLN----GYSVN-EPSSLIENNSTSQ---------------QCQNPI I KPQTSTVSPAFPILTMPTP --KEFQLLVMNADHRDYTSELNAGKTSPELSTGDLTEPCKT-----FP--SPHHE-----------SNTTTPPPIP-A KKKEFQLLVVNADVGGYTSELDAGKMSARLPTGRASQPAPTED-SSLVQGQPFGEYQSLYFEAEMPPIPPASPVSPLPPV PRKEFQLLVVNADRGGYTTELDAGKMSAKLPTGRGSQPAPTED-SRLVQGQPFGEYQSLYFEAEMPPIPPTSPVSPLLPL PRKEFOLLVVNADGGGYTTELDAGKMSAKLPTGRSSOPAPTED-SRLVOGOPFREYOSLYFEAEMPPIPPASPVSPLIPL KRNEFQLLVVNADVGGYTSELDAGKMSARLPTGRASQPAPTED-SSLVQGQPFGEYQSLYFEAEMPPIPPASPVSPLLPV KRKEFOLIVVNADGGGYTTELDAGKMSAKI PTGRGSQPAPTED SRLVQGQPEGEYQSIYFEAEMPPIPPASPVSSLL KRKEFQLLVVNADVGGYTSELDAGKLSARLPTGRASQPASTED-SSLVQGQPFGEYQSLYFEAEMPPIPPASPVSPLPPV

$* * * * *$ $\underset{\star \star * *}{\Delta}$

PVYTVVEGVDRQNSLLLTPNSTPAPQLIIPK---TMPTPGGYLTPDLLGSITP-PVYTVVEGVDRQNSLLLTPNSTPAPQLIIPK---TMPTPGGYLTPDLLGSITP-PEYTMVDGVGWKDSLLIKTSSATESSFAAPK---SGPTPEGYWTPDLLHSITTNK PVYTVVEGVDRQNSLLLSPNSAPAPHLIIPK---NMPTPDGYLTADLLGSITP-SAYTMVEGVGRQNSLLLKPGPTPAPQPVLTKLPLPTPTPEGYLTPDLLGNITP-SVYTMVEGVDRONSLLLKPSPPPAPHPVLTKLPLPTPTPEGYLTPDLLGNITP-SVYTMVEGVDRONS LLIKPS P P PAPQPVLTKLPLPTGTPEGYLT PDLLGNITP-SAYTMVEGVDRQNS LLLKPGPTPAPQPDVTKLPLPTPTPEGYLTPDLLGNITP-SVYTMVEGVDRQNSLLLKPS P P PAPQPVLTKLPLPT PTPEGYLTPDLLGNVTP- SAYTMVEGVDRQNSLLLKPGPTPAPQTVLTKLPLPTPTPEGYLTPDLLGNITP--

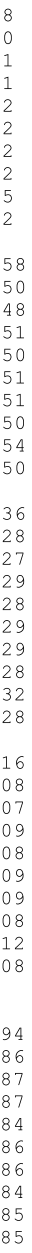

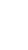

-10
9

228


Table 3 Amino acid sequence similarities among teleostean GHR2s

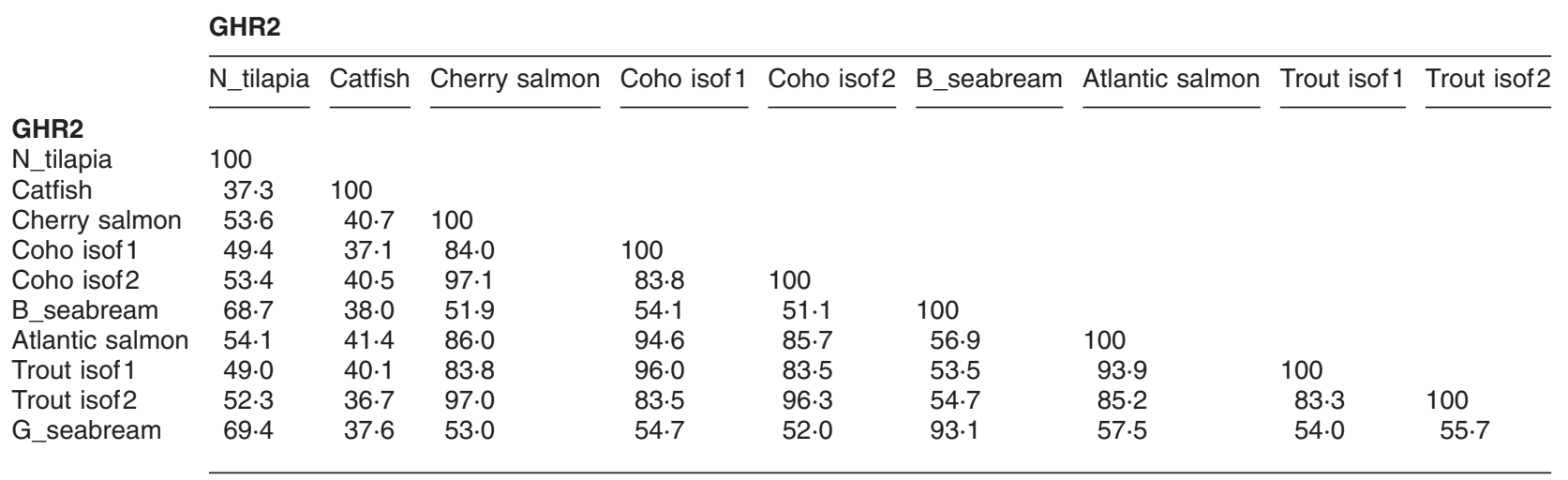

The Clustal method of the DNASTAR software was employed to compare the fish GHR2 aa sequences. Data are expressed as percentage aa identity. B_seabream, black seabream GHR; Trout isof 1, rainbow trout GHR isoform 1; isof2, isoform 2; Coho isof 1, coho salmon GHR isoform 1; isof2, isoform 2; M_tilapia, Mozambique tilapia; N_tilapia, Nile tilapia.

promoter, the $\beta$-casein promoter or the c-fos promoter activities via either sbGHR1 or sbGHR2.

\section{Differential regulation of sbGHR1 and sbGHR2 expression in seabream liver in vivo}

In vivo expression of sbGHR1 and sbGHR2 in seabream liver under various hormonal stimulations was investigated (Fig. 8). A significant increase of sbGHR1 expression in the liver was found when the fish was injected with cortisol. The same treatment with cortisol, however, could not elicit any changes in sbGHR2 gene expression in the fish liver. On the other hand, testosterone significantly decreased sbGHR2 gene expression in the fish liver but not sbGHR1. Expression of both sbGHR1 and sbGHR2 was suppressed by estradiol and ipamorelin administration, but not by sbGH.

\section{Discussion}

The present study provides evidence for the concomitant existence of two GHR subtypes in a single fish species in different teleost lineages. Both GHR subtypes in fish were shown, for the first time, to be functionally active. In seabream the two GHR subtypes were found to exhibit different patterns of tissue distribution and post-receptor signaling events. They are also subjected to different transcriptional regulation by various hormone treatments.

Structural analysis of the GHR2 sequences reported herein and those reported in salmonid species and gilthead seabream reveal that GHR2 in fish possesses structural features distinct from the conventional GHR1 which is more akin structurally to the non-teleost GHR. Notably, GHR2 contains 4 to 5 extracellular cysteines instead of 6 to 7 in GHR1. In sbGHR1, disulfide bonds could form between the following pairs of cysteine residues: C54/C64, C97/C107, and C121/C138 (Fig. 2), according to their homologous positions on human GHR (Fuh et al. 1990). Cysteine residues corresponding to $\mathrm{C} 54, \mathrm{C} 64, \mathrm{C} 97$ and $\mathrm{C} 107$, but not $\mathrm{C} 121$ and $\mathrm{C} 138$ of sbGHR1, could be found in fish GHR2 (Fig. 4). Although it is not known at the present stage if this extra pair of cysteine in GHR1 accounts for any variance between GHR1 and GHR2 in terms of the topology of their extracellular domains, its absence in all GHR2 sequences appears to be a characteristic feature. A highly conserved intracellular motif is found between D367 and L381 of sbGHR2. This motif, which is identical in all fish GHR2 sequences known to date, is not present in GHR1. Further studies on the biological significance of this unique GHR2 motif are highly warranted.

Expression of the cloned receptors in cultured eukaryotic cells followed by functional assays using

Figure 4 Multiple alignment of all the fish GHR2 sequences known to date. Identical aa sequences are indicated by asterisks above the sequences. The conserved cysteine residues in the extracellular domain are shaded in dark. The FG(E/D)FS motif is boxed by an open rectangle. The transmembrane domain is underlined with two solid lines. The Box 1 and Box 2 regions are shaded in gray. The conserved tyrosine resides in the intracellular domain are highlighted by dark triangles underneath the sequences. Gaps were introduced for maximal similarity. The fish species included in this comparison are: black seabream (B_seabream), gilthead seabream (G_seabream), Southern catfish (Catfish), Nile tilapia (Tilapia), coho salmon isoform 1 (Coho 1), coho salmon isoform 2 (Coho 2), cherry salmon (Cherry), rainbow trout isoform 1 (Trout 1) and isoform 2 (Trout 2), Atlantic salmon (A_salmon). 


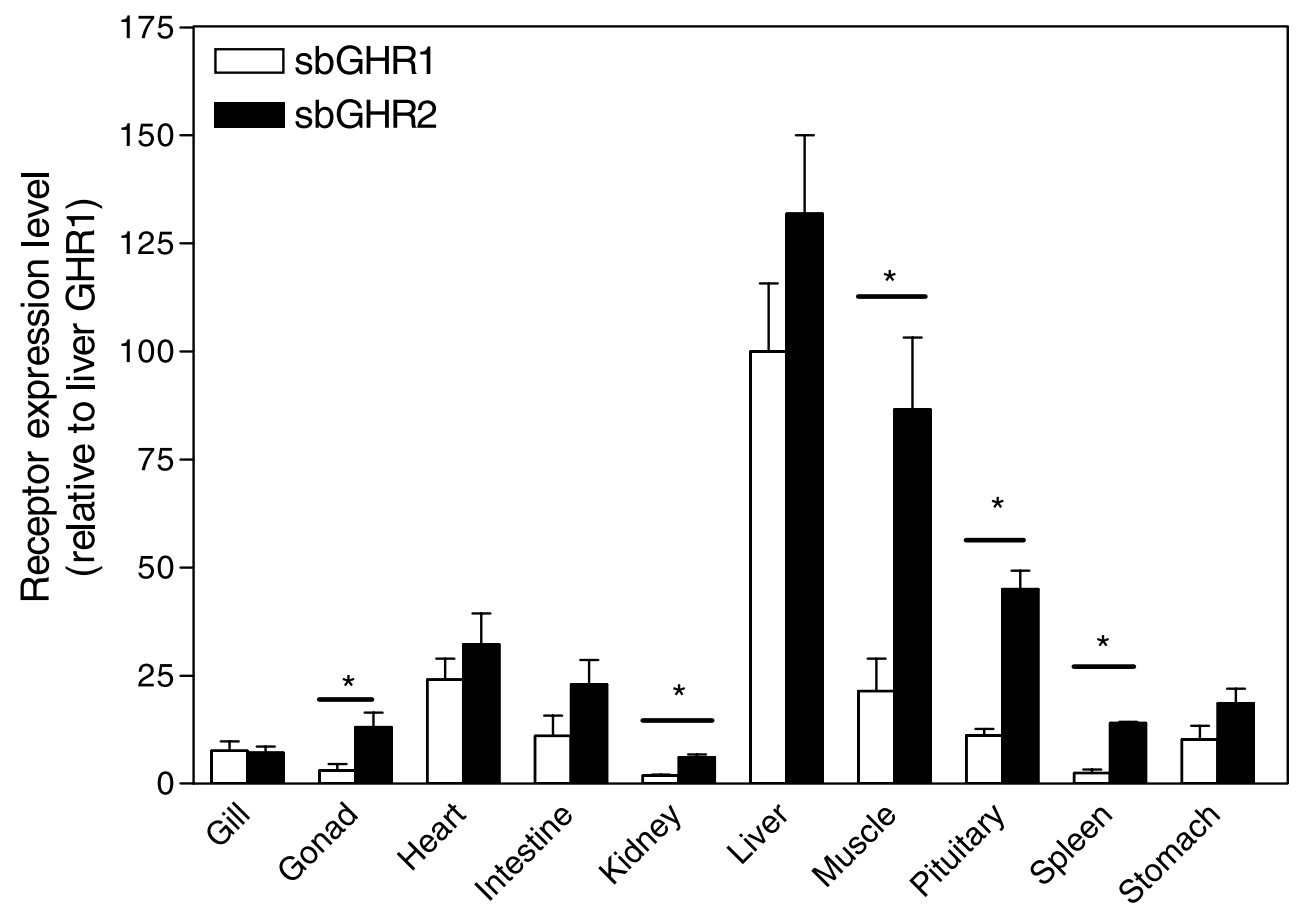

Figure 5 Distribution of sbGHR1 and sbGHR2 in seabream tissues. Results are normalized against $\beta$-actin expression and are expressed as mean values \pm S.E.M. from six fishes. Significant difference revealed by unpaired $t$-test between sbGHR1 and sbGHR2 expression in each tissue type is marked by asterisks $\left({ }^{*}, P<0.05\right)$.

specific promoter-driven reporter gene expression in the present study indicated that sbGHR2 is indeed a functional entity capable of transducing post-receptor signaling events. Both sbGHR1 and sbGHR2 could activate the Spi $2 \cdot 1$ and $\beta$-casein promoters upon receptor stimulation. It has been reported previously that association of JAK2 to the Box 1 motif as well as the presence of the C-terminal portion of the intracellular tail are essential in mediating Spi $2 \cdot 1$ promoter activation by mammalian GHR (Goujon et al. 1994, Sotiropoulos et al. 1994, Dinerstein et al. 1995, Gong et al. 1998). Moreover, rat GHR was able to activate the $\beta$-casein promoter by stimulating the phosphorylation of the signal transducers and activators of transcription(STAT) 1 and STAT5 proteins (Smit et al. 1997, Gerland et al. 2000). In view of the fact that both sbGHR 1 and sbGHR2 are able to activate these promoters, a similar signal transduction pathway is probably conserved in fish. Nevertheless, the efficacies of the receptor-mediated promoter activation for sbGHR2 are much lower than sbGHR1. This could be attributed to the following possibilities. First, a reduced number of disulfide linkages in the extracellular domain of sbGHR2 might result in a less rigid ligand binding domain essential for maximal interaction with the ligand. Second, the missing of some intracellular tyrosine residues in sbGHR2 might explain the reduced efficiency of signal transduction, as these intracellular tyrosine residues have been reported to be involved in the GH-dependent phosphorylation of STAT5 (Herrington et al. 2000).

Interestingly, only sbGHR1 but not sbGHR2 could trigger the c-fos promoter activation. The significance of this difference in signal transduction between the two receptor subtypes remains to be elucidated. GH-induced tyrosyl phosphorylation of STAT1 and STAT3 in mammalian GHR is followed by the binding of these STATs to the sis inducible element (SIE) of c-fos. The phosphorylated tyrosines in the N-terminal half of the cytoplasmic domain of the rat GHR are thought to contribute towards maximal activation of STAT1 and STAT3 in response to GH stimulation (Herrington et al. 2000). In comparison with sbGHRl, two tyrosine residues (Y331 and Y400 of sbGHR1, Fig. 2) are absent in the same region in sbGHR2, and this might account for the inactivity of sbGHR2 towards the c-fos promoter.

Recently, it has been reported that the sSL receptor bears a relatively high sequence homology to GHR in teleosts (Fukada et al. 2005). The possibility therefore arises that this sbGHR2 could be the SL receptor in seabream. This is however unlikely. Amino acid sequence comparison indicated that a higher sequence identity in fact exists between sbGHR 1 and sSL receptor $(59 \%)$ than that between sbGHR2 and sSL receptor $(46.8 \%)$, suggesting that the sbGHR2 reported herein is 
A

Spi 2.1 promoter activity

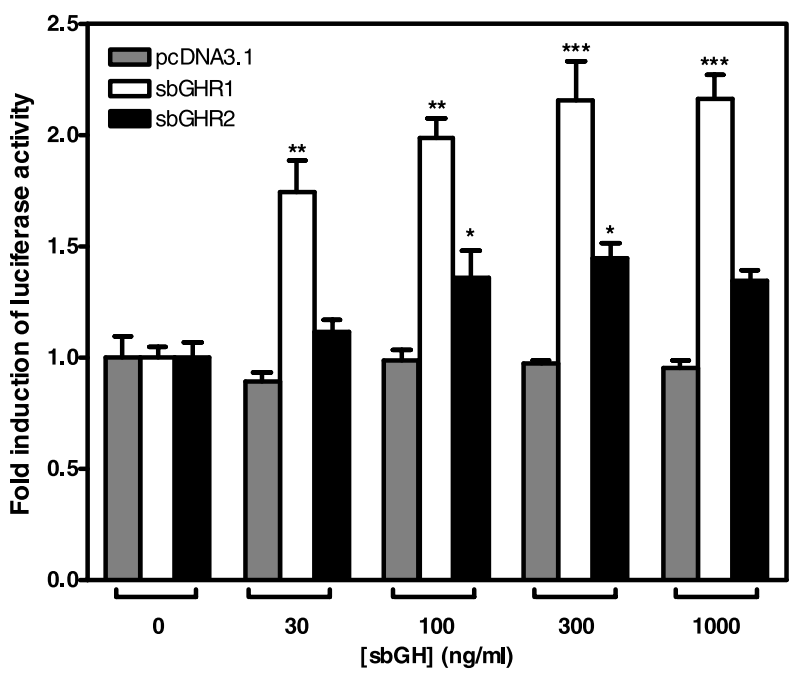

$\mathbf{C}$ c-fos promoter activity

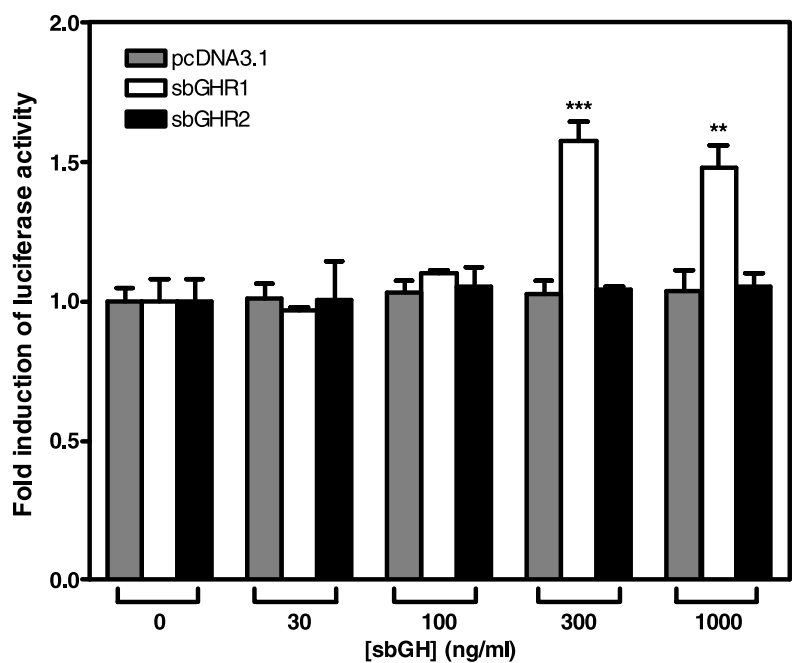

B

$\beta$-casein promoter activity

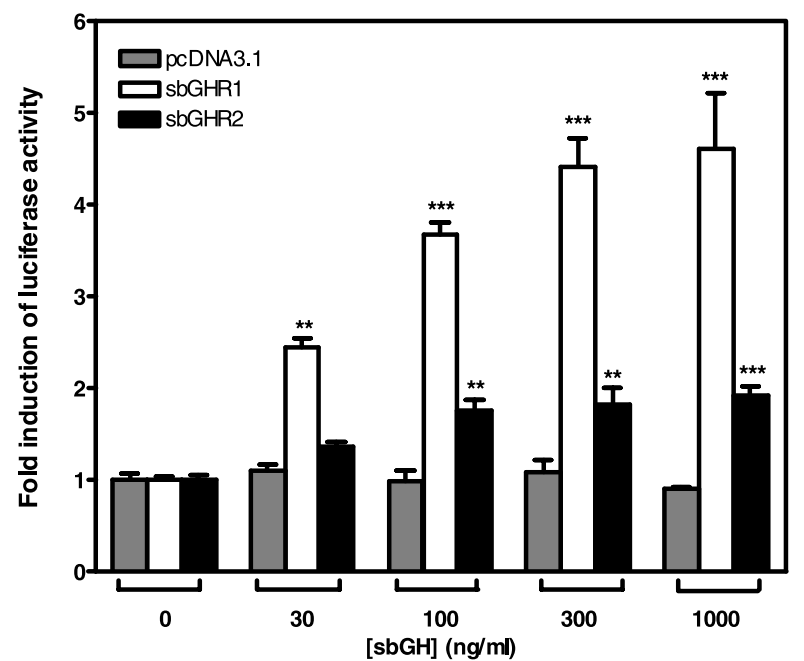

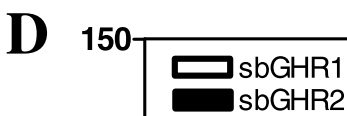

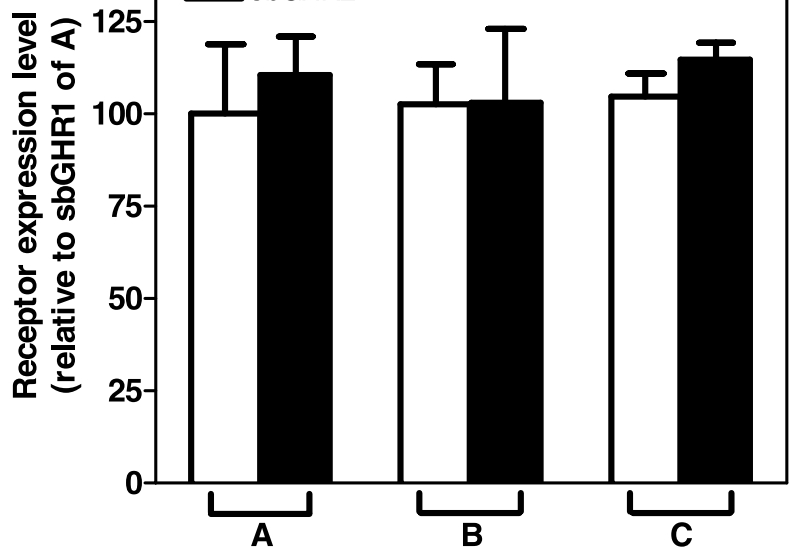

Figure 6 Transactivation of the different promoters in CHO-K1 cells expressing sbGHR1 and sbGHR2. CHO-K1 cells were co-transfected with a pcDNA3.1 vector containing the entire coding region of sbGHR1 or sbGHR2 together with a luciferase reporter plasmid driven by the Spi 2.1 promoter (Panel A), the $\beta$-casein promoter (Panel B), or the c-fos promoter (Panel C). An empty vector transfection was performed in parallel as the negative control. The transfected cells were subsequently stimulated by different concentrations of sbGH as indicated on the $\mathrm{x}$-axis. The expression levels of the two receptor subtypes in the transfected cells (from Panels A, B and C) were determined by RT-PCR (Panel D). Results are expressed as mean values \pm S.E.M. $(n=6)$. ( ${ }^{*}, P<0.05 ;{ }^{* *}, P<0.01 ;{ }^{* * *}, P<0.001$ as compared with the respective control by one-way ANOVA.)

unlikely to be a SL receptor. Moreover, we have tested its ligand specificity towards sGH, sPRL and sSL. Neither sPRL nor sSL could elicit any activation of the Spi $2 \cdot 1$ promoter or the $\beta$-casein promoter via sbGHR2. Similar to sbGH, sGH was able to activate sbGHR2. However, it should be noted that the use of heterologous hormones in this ligand specificity study is not the most ideal, and further confirmation awaits the availability of homologous hormones from black seabream.

Although sbGHR1 and sbGHR2 are present in all the tissues examined, the expression of sbGHR2 is significantly higher than sbGHRl in many tissues examined including the gonad, kidney, muscle, pituitary and spleen. The physiological significance of the higher expression of sbGHR2 is not known at present but we 
A

Spi 2.1 promoter activity

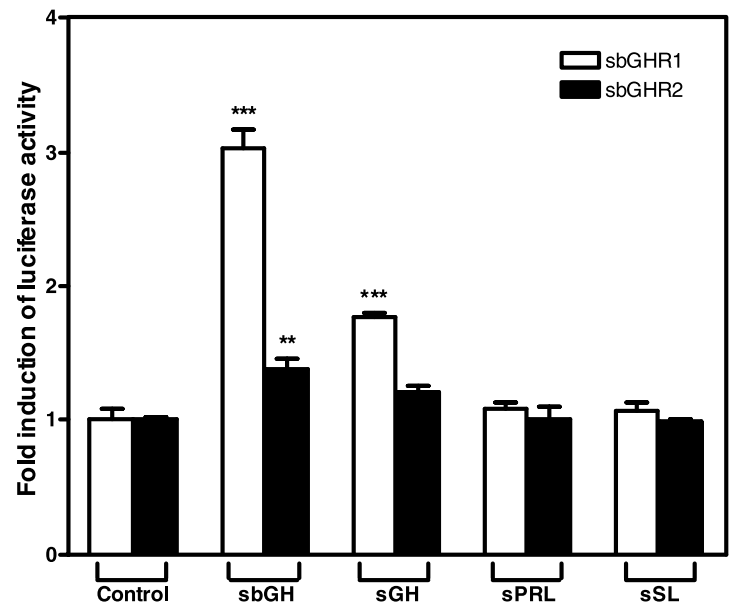

B

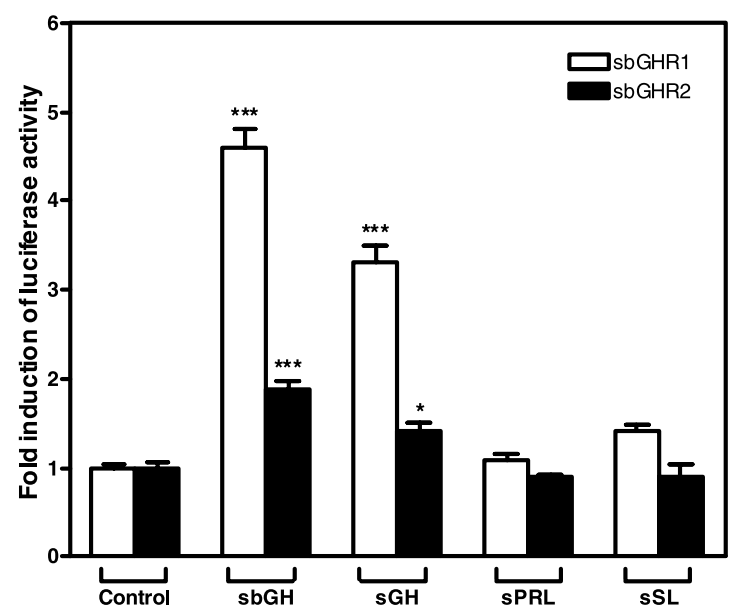

C c-fos promoter activity

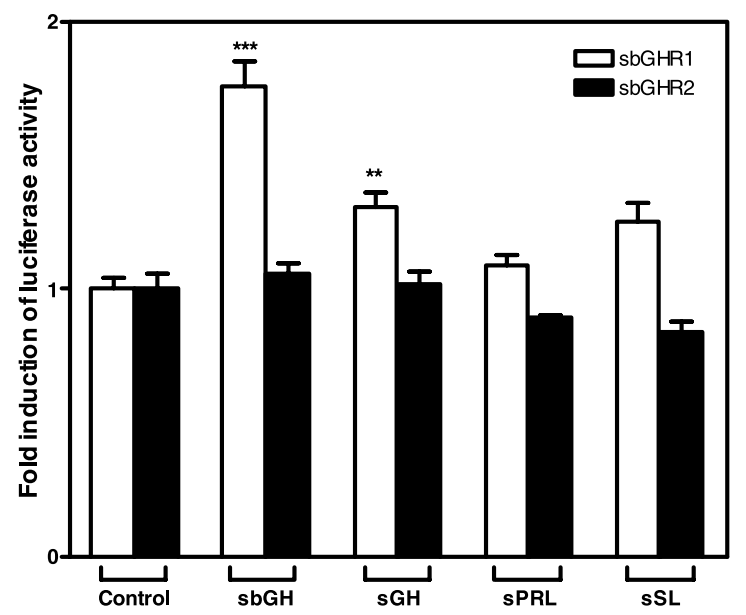

postulate that sbGHR2 might serve as a modulator to GH signaling since a lower efficacy of sbGHR2activated signal transduction is invariably observed. This phenomenon of a receptor being attenuated by another related receptor subtype has been observed in a number of cases. These include the estrogen receptor (ER) in which $\operatorname{ER} \beta$ was demonstrated to play a role in modulating the effects of ER $\alpha$ (Zhang et al. 2000), the interleukin (IL)-6 receptor in which the $\delta 4$ isoform acts as a competitor of ligand binding terminating the cytokine-induced signal transduction (Bihl et al. 2002), and the growth hormone secretagog receptor (GHSR) in which the GHSR-1b subtype attenuates the signaling of the GHSR-la subtype (Chan \& Cheng 2004). Whether the same principle applies to sbGHR1 and sbGHR2 here awaits further studies. However, the possibility that sbGHR2 might activate other signaling pathways could not be excluded. Further investigations on the functional significance of possessing two receptor subtypes at the same time are highly warranted. Interestingly, the relative expression level of sbGHR1 and sbGHR2 in the liver and muscle is different from that reported in gilthead seabream (Saera-Vila et al. 2005). In gilthead seabream, the expression of GHR2 in the liver is lower than that of GHR1 whereas GHR2 expression in the muscle is similar to that of GHR1. In our case, we have observed a very different expression pattern of these two receptor subtypes in black seabream in which the expression of sbGHR2 is much higher than sbGHR 1 in many tissues examined. An explanation for this apparent dichotomy in receptor subtype expression in the two seabream species remains elusive. The time of tissue sampling could be a possible reason since temporal variation in GHR expression has been reported in some fish species (Wargelius et al. 2005). The extent of feeding is another possibility since satiety and starvation could affect GHR expression (Deng et al. 2004, Fukada et al. 2004).

To date, information on the hormonal regulation of GHR expression in teleosts is very limited despite the cloning of the GHR sequences from a number of fish species. For example, information regarding cortisol regulation of hepatic GHR expression is scarce.

Figure 7 Transactivation of the different promoters in $\mathrm{CHO}-\mathrm{K} 1$ cells expressing sbGHR1 or sbGHR2 under various hormone stimulation. $\mathrm{CHO}-\mathrm{K} 1$ cells were co-transfected with a pcDNA3. 1 vector containing the entire coding region of sbGHR1 or sbGHR2 together with a luciferase reporter plasmid driven by the Spi 2.1 promoter (Panel $A)$, the $\beta$-casein promoter (Panel B), or the c-fos promoter (Panel C). The transfected cells were subsequently stimulated by different hormones as indicated on the $x$-axis at $300 \mathrm{ng} / \mathrm{ml}$. Results are expressed as mean values \pm S.E.M. $(n=6)$. $\left({ }^{*}, P<0.05 ;{ }^{* *}\right.$, $P<0.01 ;{ }^{* \star}, P<0.001$ as compared with the respective control by one-way ANOVA.) (sbGH: seabream $\mathrm{GH}$; sGH: salmon $\mathrm{GH}$; SPRL: salmon PRL; SSL: salmon SL.) 

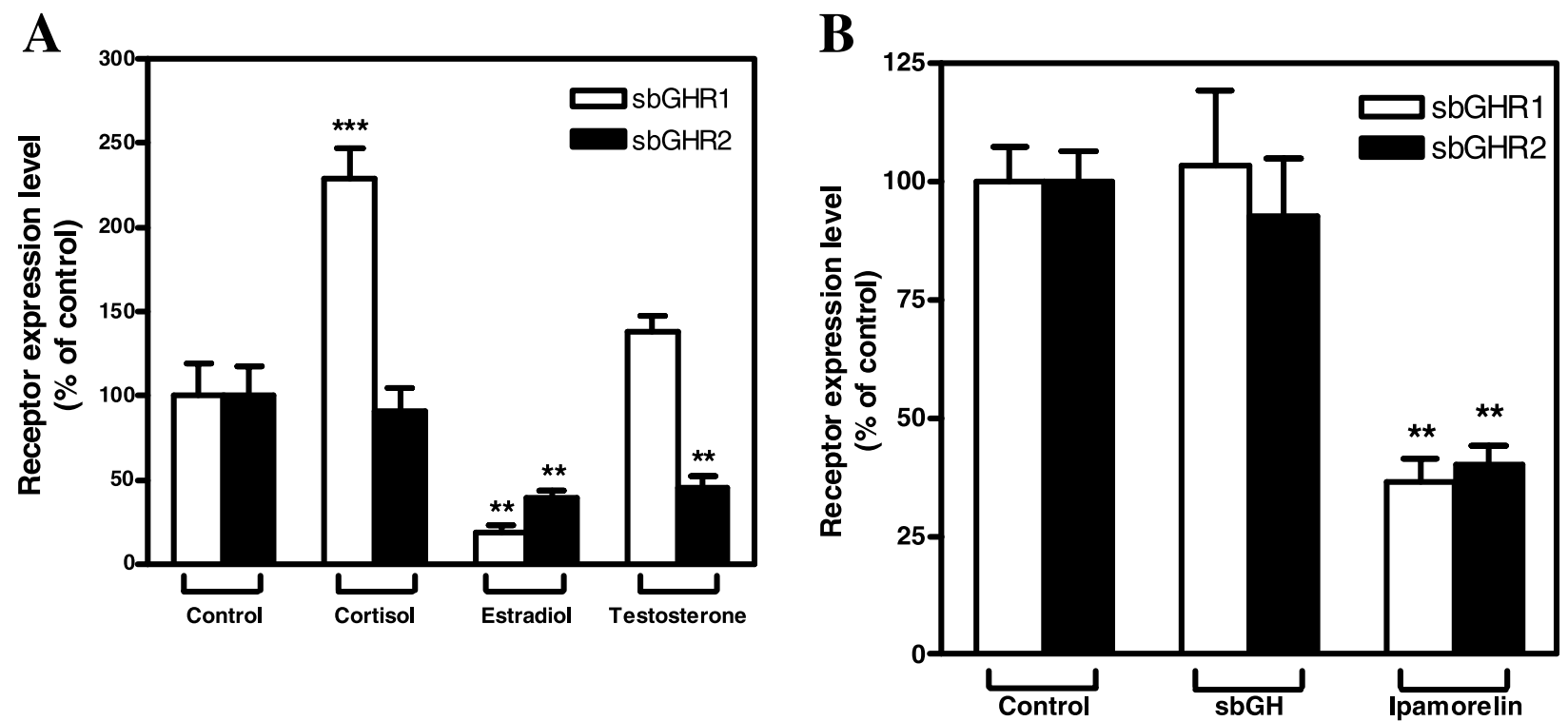

Figure 8 In vivo regulation of sbGHR1 and sbGHR2 expression in seabream liver by hormone treatment. Results are expressed as mean values \pm S.E.M. from six independent fishes. ( ${ }^{* *}, P<0.01$; ${ }^{* * *}, P<0.001$ as compared with the respective control by one-way ANOVA.) The hormone concentrations used were: $5 \mu \mathrm{g} / \mathrm{g}$ cortisol, $2 \mu \mathrm{g} / \mathrm{g}$ estradiol, $2 \mu \mathrm{g} / \mathrm{g}$ testosterone, $1 \mu \mathrm{g} / \mathrm{g}$ sbGH and $10 \mathrm{ng} / \mathrm{g}$ ipamorelin. Olive oil (for the control group in Panel A) and $0.8 \% \mathrm{w} / \mathrm{v} \mathrm{NaCl}$ solution (for the control group in Panel B) were used as the vehicle control.

In mammals, GHR mRNA level was reported to be increased in the fetal ovine liver by cortisol ( $\mathrm{Li}$ et al. 1999). On the other hand, administration of cortisol to coho salmon did not increase hepatic GH binding (Gray et al. 1992). In the present study, cortisol was found to upregulate sbGHR1 expression but not sbGHR2 in black seabream. It has been reported recently that cortisol could elicit metabolic changes in seabream liver by decreasing the glucose-6-phosphate dehydrogenase (G6PDH) activity (Laiz-Carrion et al. 2003). The enhanced expression of sbGHRl by cortisol might provide a possible explanation for this report since $\mathrm{GH}$ has been shown to reduce hepatic G6PDH activity in fish (Leena et al. 1999).

Reports on the actions of androgens on growth in teleosts are controversial. On one hand, methyltestosterone was reported to increase growth in tilapia (Riley et al. 2002, Sparks et al. 2003). On the other hand, both testosterone and methyltestosterone were demonstrated to decrease growth in perch (Mandiki et al. 2004, Mandiki et al. 2005). These ambivalent actions of androgens are reflected in the effects of the steroids on the GH level in fish. For example, testosterone was demonstrated to exhibit dose-dependent stimulation of the pituitary GH mRNA level in goldfish (Huggard et al. 1996). Also, plasma GH level was increased after testosterone administration in fasted rainbow trout (Holloway \& Leatherland 1997). In salmon, however, both testosterone and 11-ketotestosterone were demonstrated to increase plasma insulin-like growth factor
(IGF)-I level without affecting the GH level (Larsen et al. 2004). So far no information is available on whether testosterone affects the expression of GHR in teleosts. From our in vivo studies, testosterone was found to decrease hepatic sbGHR2 expression but not sbGHR1 in black seabream. If our postulation that sbGHR2 could act as a negative modulator of GH signaling prevails, then this downregulation of sbGHR2 in the liver of the seabream by testosterone would bear important physiological implications. The decreased sbGHR2 level would release the negative modulatory action on sbGHRl thereby enhancing the biological action of GH.

There is also no report so far on the regulation of GHR expression in teleosts by estradiol. In the present study, the expression of both sbGHR 1 and sbGHR2 was found to be decreased by estradiol treatment in black seabream. This decreased receptor expression in the seabream liver by estradiol in fact provides an explanation to a recent report that estradiol decreases GH-stimulated expression of IGF-I mRNA in the seabream liver (Carnevali et al. 2005). In mammals, rather diverse observations on estradiol regulated GHR expression have been reported. It has been shown that estradiol caused a reduction of GHR expression in the rabbit liver (Domene et al. 1994) but an elevated GHR mRNA was detected in the rat liver by estradiol (Carmignac et al. 1993, Gabrielsson et al. 1995). The estradiol-induced GHR expression in mouse was found to be GH dependent in which only a combination of 
estradiol and GH could upregulate hepatic GHR expression (Contreras \& Talamantes 1999). It is not known whether the species variation observed in mammals is also seen in teleosts. In this context, it is noteworthy to mention the results of Kajimura et al. (2004) that a high plasma estradiol level did not correlate with an elevation of hepatic GHR expression in tilapia. Nonetheless, the present study is the first report demonstrating that GHR expression in fish could be regulated by both estradiol and testosterone, constituting a new target for the actions of steroid hormones on the growth axis in teleosts.

Another interesting observation is that ipamorelin, a synthetic growth hormone secretagogue (GHS) which has been shown to exert potent stimulatory effect on GH secretion in seabream (Chan et al. 2004), downregulates both sbGHR1 and sbGHR2 in seabream liver. Since GHSR is also present in the seabream liver (Chan \& Cheng 2004), this decreased expression of sbGHRs could be a direct action of ipamorelin on the seabream liver. In line with this, treatment by sbGH alone did not cause any significant alteration in the expression of either sbGHR1 or sbGHR2 in the seabream liver. In mammals, it has been reported that GHS could induce an elevation of GHR in the liver of uremic rats (Krieg et al. 2002). However, no studies have been performed so far on GHS-regulated GHR expression in teleosts or in normal mammals. Our observation reported herein thus opens up new avenues in studying the regulation of GHR expression in fish.

Genomic data indicate that the genomes of most vertebrates (including human) had undergone two whole genome duplications in their evolutionary history, i.e. the 2 round (2R) hypothesis (Ohno 1970), while the genomes of most bony fishes had undergone an additional duplication (the fish-specific genome duplication (FSGD) or the 3R duplication) at the origin of modern fish (Amores et al. 1998, Hoegg et al. 2004, Meyer \& Van de Peer 2005). FSGD probably occurred after the bichirs (Polypteriformes), sturgeons (Acipenseriformes), gars and bowfins (Semionotiformes) branched off from the fish stem lineage (Hoegg et al. 2004). In the present study, two GHR subtypes encoded by two different genes were found in three different teleost species. Phylogenetic analysis of all known GHR sequences revealed that the occurrence of two GHR subtypes exists only in teleost fish. We have also searched the genomes of Xenopus, chicken, mouse, rat and human but failed to obtain any GHR2-like sequences by in silico analysis. Hence we propose that the GHR2 sequences probably originated from the FSGD event associated with the emergence of modern teleosts, and therefore most teleosts with the possible exception of bichirs, sturgeons, gars and bowfins should possess both GHR subtypes unless they had experienced a secondary loss after the FSGD event, pending experimental proof. This notion of two GHR subtypes is entirely different from the reported GHR isoforms in eel and in salmonids. As can be viewed from our phylogenetic tree (Fig. 3), both the two GHR isoforms in eel belong to the GHR 1 clade and both the two GHR isoforms in coho salmon belong to the GHR2 clade. However, the two GHR subtypes from seabream, catfish and tilapia reported herein were segregated into the two separate clades. Salmonids have undergone a $4 \mathrm{R}$ duplication, which is supported by the fact that these fishes possess close to 16 genes of a conserved gene family (i.e. the Hox genes) (Moghadam et al. 2005). Thus there might be multiple GHRs in salmonids. The GHRs cloned in salmonids so far all belong to the GHR2 subtype. We postulate that GHR1s can also be found in salmonids, again pending actual experimental evidence. The story in eel might be more complicated. Eels diverged earlier than most other teleosts (Colbert \& Morales 1991). They are more akin to the primitive bony fishes (Suzuki et al. 1999). Till now, studies on eel genome or gene duplication are very scarce so that the significance and implication of having two GHR1s in eel is not understood at the moment. Further studies are needed to unravel these intricacies.

Duplicated genes in a genome can only be maintained if they acquire a new function or maintain only some functions of the ancestral gene (Force et al. 1999). In this study, we have demonstrated the co-existence of both GHR1 and GHR2 in black seabream, Southern catfish and Nile tilapia. Based on the gene expression results and the post-receptor signal transduction studies in seabream, it is likely that GHR2 plays a different biological role from GHR1. These functional differences probably explain and justify the preservation and co-existence of both GHR subtypes during teleostean evolution after genome duplication. Further dissection of such functional differences between GHR1 and GHR2 in fish is highly warranted.

\section{Acknowledgements}

We thank Dr Nils Billestrup of the Hagedorn Research Institute in Denmark for providing the rat Spi $2 \cdot 1$ promoter construct, and Dr KL Yu at the University of Hong Kong for providing the rat $\beta$-casein and human c-fos promoter constructs. We are also grateful to Dr Penny Swanson at the Northwest Fisheries Science Center, USA for providing us with the purified salmon growth hormone, prolactin and somatolactin preparations. The following grant agencies (to $\mathrm{CHKC}$ ) are gratefully acknowledged: Research Grants Council of the Hong Kong Government (Project no. CUHK18/ $93 \mathrm{M}$ ), Direct Grants from the Chinese University of Hong Kong, and the Lee Hysan \& Endowment Funds from United College. The authors declare that there is 
no conflict of interest that would prejudice the impartiality of this scientific work.

\section{References}

Amores A, Force A, Yan YL, Joly L, Amemiya C, Fritz A, Ho RK, Langeland J, Prince V, Wang YL, Westerfield M, Ekker M \& Postlethwait JH 1998 Zebrafish hox clusters and vertebrate genome evolution. Science 282 1711-1714.

Bihl MP, Heinimann K, Rudiger JJ, Eickelberg O, Perruchoud AP, Tamm M \& Roth M 2002 Identification of a novel IL-6 isoform binding to the endogenous IL-6 receptor. American Fournal of Respiratory Cell and Molecular Biology 27 48-56.

Calduch-Giner J, Duval H, Chesnel F, Boeuf G, Perez-Sanchez J \& Boujard D 2001 Fish growth hormone receptor: molecular characterization of two membrane-anchored forms. Endocrinology 142 3269-3273.

Calduch-Giner JA, Mingarro M, Vega-Rubin de Celis S, Boujard D \& Perez-Sanchez J 2003 Molecular cloning and characterization of gilthead sea bream (Sparus aurata) growth hormone receptor (GHR). Assessment of alternative splicing, Comparative Biochemistry and Physiology B-Biochemistry \& Molecular Biology 136 1-13.

Carmignac DF, Gabrielsson BG \& Robinson IC 1993 Growth hormone binding protein in the rat: effects of gonadal steroids. Endocrinology 133 2445-2452.

Carnevali O, Cardinali M, Maradonna F, Parisi M, Olivotto I, Polzonetti-Magni AM, Mosconi G \& Funkenstein B 2005 Hormonal regulation of hepatic IGF-I and IGF-II gene expression in the marine teleost Sparus aurata. Molecular Reproduction and Development 71 12-18.

Chan CB \& Cheng CHK 2004 Identification and functional characterization of two alternatively spliced growth hormone secretagogue receptor transcripts from the pituitary of black seabream Acanthopagrus schlegeli. Molecular and Cellular Endocrinology 214 81-95.

Chan CB, Fung CK, Fung W, Tse MC \& Cheng CHK 2004 Stimulation of growth hormone secretion from seabream pituitary cells in primary culture by growth hormone secretagogues is independent of growth hormone transcription. Comparative Biochemistry and Physiology C-Toxicology \& Pharmacology 139 77-85.

Colbert EH \& Morales M 1991 Evolution of the vertebrates $4^{\text {th }}$ edn, New York: Wiley-Liss.

Contreras B \& Talamantes F 1999 Growth hormone (GH) and $17 \beta$-estradiol regulation of the expression of mouse GH receptor and GH-binding protein in cultured mouse hepatocytes. Endocrinology 140 4725-4731.

Deng L, Zhang WM, Lin HR \& Cheng CHK 2004 Effects of food deprivation on expression of growth hormone receptor and proximate composition in liver of black seabream Acanthopagrus schlegeli. Comparative Biochemistry and Physiology 137 421-432.

Dinerstein H, Lago F, Goujon L, Ferrag F, Esposito N, Finidori J, Kelly PA \& Postel-Vinay MC 1995 The proline-rich region of the $\mathrm{GH}$ receptor is essential for JAK2 phosphorylation, activation of cell proliferation, and gene transcription. Molecular Endocrinology 9 1701-1707.

Domene HM, Marin G, Sztein J, Yu YM, Baron J \&. Cassorla FG 1994 Estradiol inhibits growth hormone receptor gene expression in rabbit liver. Molecular and Cellular Endocrinology 103 81-87.

Force A, Lynch M, Pickett FB, Amores A, Yan YL \& Postlethwait J 1999 Preservation of duplicate genes by complementary, degenerative mutations. Genetics 151 1531-1545.

Fuh G, Mulkerrin MG, Bass S, McFarland N, Brochier M, Bourell JH, Light DR \& Wells JA 1990 The human growth hormone receptor. Secretion from Escherichia coli and disulfide bonding pattern of the extracellular binding domain. Fournal of Biological Chemistry 265 3111-3115.
Fukada H, Ozaki Y, Pierce AL, Adachi S, Yamauchi K, Hara A, Swanson P \& Dickhoff WW 2004 Salmon growth hormone receptor: molecular cloning, ligand specificity, and response to fasting. General and Comparative Endocrinology 139 61-71.

Fukada H, Ozaki Y, Pierce AL, Adachi S, Yamauchi K, Hara A, Swanson P \& Dickhoff WW 2005 Identification of the salmon somatolactin receptor, a new member of the cytokine receptor family. Endocrinology 146 2354-2361.

Gabrielsson BG, Carmignac DF, Flavell DM \& Robinson IC 1995 Steroid regulation of growth hormone $(\mathrm{GH})$ receptor and GH-binding protein messenger ribonucleic acids in the rat. Endocrinology 136 209-217.

Gerland K, Bataille-Simoneau N, Basle M, Fourcin M, Gascan H \& Mercier L 2000 Activation of the Jak/Stat signal transduction pathway in GH-treated rat osteoblast-like cells in culture. Molecular \& Cellular Endocrinology 168 1-9.

Gong TW, Meyer DJ, Liao J, Hodge CL, Campbell GS, Wang X, Billestrup N, Carter-Su C \& Schwartz J 1998 Regulation of glucose transport and c-fos and egr-1 expression in cells with mutated or endogenous growth hormone receptors. Endocrinology $1391863-1871$.

Goujon L, Allevato G, Simonin G, Paquereau L, Le Cam A, Clark J, Nielsen JH, Djiane J, Postel-Vinay MC, Edery M \& Kelly PA 1994 Cytoplasmic sequences of the growth hormone receptor necessary for signal transduction. PNAS 91 957-961.

Govers R, ten Broeke T, van Kerkhof P, Schwartz AL \& Strous GJ 1999 Identification of a novel ubiquitin conjugation motif, required for ligand-induced internalization of the growth hormone receptor. EMBO fournal 18 28-36.

Gray ES, Kelley KM, Law S, Tsai R, Young G \& Bern HA 1992 Regulation of hepatic growth hormone receptors in coho salmon (Oncorhynchus kisutch). General and Comparative Endocrinology 88 243-252.

Harms CA, Kennedy-Stoskopf S, Horne WA, Fuller FJ \& Tompkins WA 2000 Cloning and sequencing hybrid striped bass (Morone saxatilis $\times M$. chrysops) transforming growth factor- $\beta$ (TGF- $\beta$ ), and development of a reverse transcription quantitative competitive polymerase chain reaction (RT-qcPCR) assay to measure TGF- $\beta$ mRNA of teleost fish. Fish \& Shellish Immunology 10 61-85.

Hermann JR, Miller JA, O'Neill S, Tsao TT, Harding RM \& Dale JL 2000 Single-primer amplification of flanking sequences. Biotechniques 29 1176-1178, 1180.

Herrington J, Smit LS, Schwartz J \& Carter-Su C 2000 The role of STAT proteins in growth hormone signaling. Oncogene $\mathbf{1 9}$ 2585-2597.

Hoegg S, Brinkmann H, Taylor JS \& Meyer A 2004 Phylogenetic timing of the fish-specific genome duplication correlates with the diversification of teleost fish. Fournal of Molecular Evolution $\mathbf{5 9}$ 190-203.

Holloway AC \& Leatherland JF 1997 Effect of gonadal steroid hormones on plasma growth hormone concentrations in sexually immature rainbow trout, Oncorhynchus mykiss. General and Comparative Endocrinology 105 246-254.

Huggard D, Khakoo Z, Kassam G, \& Habibi HR 1996 Effect of testosterone on growth hormone gene expression in the goldfish pituitary. Canadian Fournal of Physiology and Pharmacology $\mathbf{7 4}$ 1039-1046.

Kajimura S, Kawaguchi N, Kaneko T, Kawazoe I, Hirano T, Visitacion N, Grau EG \& Aida K 2004 Identification of the growth hormone receptor in an advanced teleost, the tilapia (Oreochromis mossambicus) with special reference to its distinct expression pattern in the ovary. Fournal of Endocrinology 181 65-76.

Kopchick JJ \& Andry JM 2000 Growth hormone (GH), GH receptor, and signal transduction. Molecular Genetics and Metabolism $71293-314$

Krieg RJ Jr, Chan W, Lin KC, Kuemmerle NB, Veldhuis JD \& Chan JC 2002, Growth hormone and growth hormone-related mRNA in uremic rats: effect of a growth hormone secretagogue. Pediatric Nephrology 17 585-590. 
Laiz-Carrion R, Martin Del Rio MP, Miguez JM, Mancera JM \& Soengas JL 2003 Influence of cortisol on osmoregulation and energy metabolism in gilthead seabream Sparus aurata. Fournal of Experimental Zoology A-Comparative Experimental Biology 298 105-118.

Larsen DA, Shimizu M, Cooper KA, Swanson P \& Dickhoff WW 2004 Androgen effects on plasma GH, IGF-I, and 41-kDA IGFBP in coho salmon (Oncorhynchus kisutch). General and Comparative Endocrinology 139 29-37.

Lee LT, Nong G, Chan YH, Tse DL \& Cheng CHK 2001 Molecular cloning of a teleost growth hormone receptor and its functional interaction with human growth hormone. Gene $\mathbf{2 7 0}$ 121-129.

Leena S, Shameena B \& Oommen OV 1999 Studies on the effect of growth hormone in vivo and in vitro on lipogenic enzymes and transaminases in a teleost Anabas testudineus (BLOCH). Endocrine Research 25 341-355.

Li J, Gilmour RS, Saunders JC, Dauncey MJ \& Fowden AL 1999 Activation of the adult mode of ovine growth hormone receptor gene expression by cortisol during late fetal development. FASEB fournal 13 545-552.

Mandiki SN, Houbart M, Babiak I, Vandeloise E, Gardeur JN \& Kestemont P 2004 Are sex steroids involved in the sexual growth dimorphism in Eurasian perch juveniles? Physiology \& Behavior 80 603-609.

Mandiki SN, Babiak I, Bopopi JM, Leprieur F \& Kestemont P 2005 Effects of sex steroids and their inhibitors on endocrine parameters and gender growth differences in Eurasian perch (Perca fluviatilis) juveniles. Steroids 70 85-94.

Meyer A \& Van de Peer Y 2005 From 2R to 3R: evidence for a fish-specific genome duplication (FSGD). Bioessays 27 937-945.

Moghadam HK, Ferguson MM \& Danzmann RG. 2005 Evolution of hox clusters in salmonidae: a comparative analysis between Atlantic Salmon (Salmo salar) and rainbow trout (Oncorhynchus mykiss). Fournal of Molecular Evolution 61 636-649.

Moutoussamy S, Kelly PA \& Finidori J 1998

Growth-hormone-receptor and cytokine-receptor-family signaling. European Foumal of Biochemistry 255 1-11.

Ohno S 1970 Evolution by gene duplication. New York: Springer-Verlag.

Parks CL, Chang LS \& Shenk T 1991 A polymerase chain reaction mediated by a single primer: cloning of genomic sequences adjacent to a serotonin receptor protein coding region. Nucleic Acids Research 19 7155-7160.

Poulter R \& Butler M 1998 A retrotransposon family from the pufferfish (fugu) Fugu rubripes. Gene 215 241-249.

Riley LG, Richman NH 3rd, Hirano T \& Gordon GE 2002 Activation of the growth hormone/insulin-like growth factor axis by treatment with $17 \alpha$-methyltestosterone and seawater rearing in the tilapia, Oreochromis mossambicus. General and Comparative Endocrinology 127 285-292.

Saera-Vila A, Calduch-Giner JA \& Perez-Sanchez J 2005 Duplication of growth hormone receptor (GHR) in fish genome: gene organization and transcriptional regulation of GHR type I and II in gilthead sea bream (Sparus aurata). General and Comparative Endocrinology 142 193-203.

Sakamoto T, Shepherd BS, Madsen SS, Nishioka RS, Siharath K, Richman NH 3rd, Bern HA \& Grau EG 1997 Osmoregulatory actions of growth hormone and prolactin in an advanced teleost. General and Comparative Endocrinology 106 95-101.
Smit LS, Vanderkuur JA, Stimage A, Han Y, Luo G, Yu-Lee LY, Schwartz J, Carter-Su C 1997 Growth hormone-induced tyrosyl phosphorylation and deoxyribonucleic binding activity of Stat5A and Stat5B. Endocrinology 138 3426-3434.

Sotiropoulos A, Perrot-Applanat M, Dinerstein H, Pallier A, Postel-Vinay MC, Finidori J \& Kelly PA 1994 Distinct cytoplasmic regions of the growth hormone receptor are required for activation of JAK2, mitogen-activated protein kinase, and transcription. Endocrinology 135 1292-1298.

Sparks RT, Shepherd BS, Ron B, Richman NH 3rd, Riley LG, Iwama GK, Hirano T \& Gordon GE 2003 Effects of environmental salinity and $17 \alpha$-methyltestosterone on growth and oxygen consumption in the tilapia, Oreochromis mossambicus. Comparative Biochemistry and Physiology B-Biochemistry \& Molecular Biology 136 657-665.

Suzuki N, Ueda K, Sakamoto H \& Sasayama Y 1999 Fish calcitonin genes: primitive bony fish genes have been conserved in some lower vertebrates. General and Comparative Endocrinology 113 369-373.

Thompson JD, Gibson TJ, Plewniak F, Jeanmougin F \& Higgins DG 1997 The CLUSTAL_X windows interface: flexible strategies for multiple sequence alignment aided by quality analysis tools. Nucleic Acids Research 24 4876-4882.

Trudeau VL 1997 Neuroendocrine regulation of gonadotrophin II release and gonadal growth in the goldfish, Carassius auratus. Reviews of Reproduction 2 55-68.

Tse DL, Tse MC, Chan CB, Deng L, Zhang WM, Lin HR \& Cheng CHK 2003 Seabream growth hormone receptor: molecular cloning and functional studies of the full-length cDNA, and tissue expression of two alternatively spliced forms. Biochimica et Biophysica Acta $\mathbf{1 6 2 5} 64-76$.

VanderKuur JA, Wang X, Zhang L, Allevato G, Billestrup N \& Carter-Su C 1995 Growth hormone-dependent phosphorylation of tyrosine 333 and/or 338 of the growth hormone receptor. Fournal of Biological Chemistry $27021738-21744$.

Very NM, Kittilson JD, Norbeck LA \& Sheridan MA 2005 Isolation, characterization, and distribution of two cDNAs encoding for growth hormone receptor in rainbow trout (Oncorhynchus mykiss). Comparative Biochemistry and Physiology B-Biochemistry \& Molecular Biology 140 615-628.

Wargelius A, Fjelldal PG, Benedet S, Hansen T, Bjornsson BT \& Nordgarden U 2005 A peak in gh-receptor expression is associated with growth activation in Atlantic salmon vertebrae, while upregulation of $i g f-I$ receptor expression is related to increased bone density. General and Comparative Endocrinology 142 163-168.

Yada T, Nagae M, Moriyama S \& Azuma T 1999 Effects of prolactin and growth hormone on plasma immunoglobulin $\mathrm{M}$ levels of hypophysectomized rainbow trout, Oncorhynchus mykiss. General and Comparative Endocrinology 115 46-52.

Zhang W, Saji S, Mäkinen S, Cheng G, Jensen EV, Warner M \& Gustafsson J-Å 2000 Estrogen receptor (ER) $\beta$, a modulator of $\mathrm{ER} \alpha$ in the uterus. PNAS 97 5936-5941.

Received in final form 19 November 2005

Accepted 23 November 2005

Made available online as an Accepted preprint on

29 November 2005 